\title{
ANALYSIS OF VEHICLE-TYPE-SPECIFIC HEADWAYS ON TWO-LANE ROADS WITH MIXED TRAFFIC
}

\author{
Rupali ROY, Pritam SAHA* \\ Dept of Civil Engineering, Indian Institute of Engineering Science and Technology, Shibpur, Howrah, India
}

Received 7 December 2017; revised 5 July 2018, 6 February 2019; accepted 1 March 2019

\begin{abstract}
Time headway is an important microscopic traffic flow parameter, which affects safety, level-of-service, capacity and traffic simulation. It is, therefore, important to know the specific distribution for a particular roadway and traffic condition. Further, headway between two vehicles depends on the type of lead vehicle and is influenced by its size and dynamics. Such impact is considerably high on two-lane roads with mixed traffic composed of a wide variety of vehicle types. This paper identified sixteen combinations of vehicle pairs and analysed vehicle-type-specific headways using field data. Appropriate distribution functions were fitted to field data and predictive models were used in understanding carfollowing behaviour. Observations indicate that quite often bike riders become reluctant in obeying lane discipline. However, car drivers show conservative attitude and usually, keep safe distance from the lead vehicle except the case when they follow another car. In addition, while following Non-Motorized Vehicles (NMV), most of the drivers keep reasonably safe distances. In this paper, a comparison of computed headway probabilities was also made with those obtained from more or less homogeneous traffic. It was found that values obtained in current study are high in most of the instances. This indicates risk-taking behaviour of driver population, which eventually affects safety of such roads. The present study, thus, demonstrates the need of investigating vehicle-type-specific headways under mixed traffic based on comprehensive field data.
\end{abstract}

Keywords: two-lane road, mixed traffic, vehicle-type-specific headway, distribution, goodness-of-fit.

\section{Introduction}

Time headway is defined as the time interval, usually measured in seconds, between successive vehicles in the traffic flow. It is an important characteristic of traffic, which affects capacity estimation, safety analysis and microscopic simulation (Ye, Zhang 2009). Performance of a simulation model is largely affected by inputs and generation of inter-arrival times or time headways is considered as a key component in regard to this (Jang et al. 2011). Further, estimated headways can be used in gap acceptance analysis and car-following behaviour studies (Ye, Zhang 2009). Thus, it is essential to know the specific headway distribution of vehicles for the study section of a road for a given flow and characteristics of traffic.

Extensive studies have been conducted on headway distributions over the decades and a large number of models have been suggested for describing the headway distribution pattern. Pearson Type III distribution (May 1990), Schuhl model (Khasnabis, Heimbach 1980), Generalized Extreme Value (GEV) distribution (Panichpapiboon 2015), inverse Weibull distribution (Riccardo, Massimil- iano 2012) were found to be fairly accurate over a range of flow levels. Couple of studies, however, indicates that different distributions may work better at different flow levels: exponential and gamma were found suitable for low to medium traffic whereas Erlang and lognormal were found to give a decent fit for high flow state (Al-Ghamdi 2001; Luttinen 1996). Mei and Bullen (1993) also, reported the use of lognormal distribution at car-following situation.

Most of these studies are based on more or less homogeneous traffic conditions characteristics of which are distinctly different, than that of mixed traffic observed on roads of most of the developing countries. Such traffic is usually composed of a wide variety of vehicles including Non-Motorized Vehicles (NMV). Speed differential of these vehicles is considerably high resulting in frequent formation of platoons since they share same road space without any physical segregation. While, at low flow, negative exponential distribution (Kumar, Rao 1998) and at medium to high flow, hyperlang distribution (Chandra, Kumar 2001) are found compatible in describing head-

${ }^{*}$ Corresponding author. E-mail: saha.pritam@gmail.com

Copyright $\odot 2020$ The Author(s). Published by Vilnius Gediminas Technical University

This is an Open Access article distributed under the terms of the Creative Commons Attribution License (http://creativecommons.org/licenses/by/4.0/), which permits unrestricted use, distribution, and reproduction in any medium, provided the original author and source are credited. 
ways under such traffic, it is invariably negative exponential distribution for a wide range of flow levels in the event of substantial percentage of smaller vehicles in the traffic (Arasan, Koshy 2003).

Impact of such traffic is, however, significantly high on two-lane roads where a single carriageway is used by both direction traffic. Faster vehicles are entrapped inside platoons and they trail one another while searching for an opportunity to pass the slower impeding one and, thereby, creating a compression of vehicles. Some impatient drivers take risk to overtake and under mixed traffic, it was observed that a few of them even dare to take considerable amount of risk while overtaking from the lower position of the platoon (Saha et al. 2017a). Compressed platoons then disperse and vehicles increase their headways. The operation is schematically shown in Figure 1, wherein it is apparent that headway of vehicles continuously changes over space and time because of such compression and decompression of vehicles. Dey and Chandra (2009) proposed lognormal distribution for describing headways on these roads in car-following state of flow.

Application of single distribution is, however, somewhat impractical especially when the proportion of shorter headways is significant. A number of mixed distribu-

a)

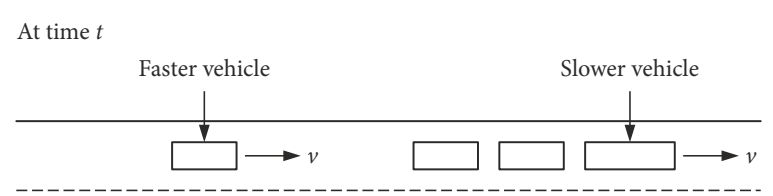

At time $t+\tau$

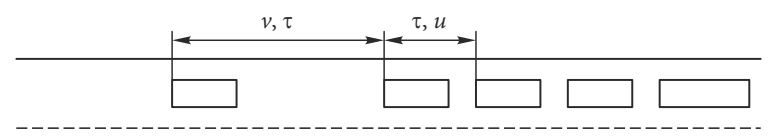

b)

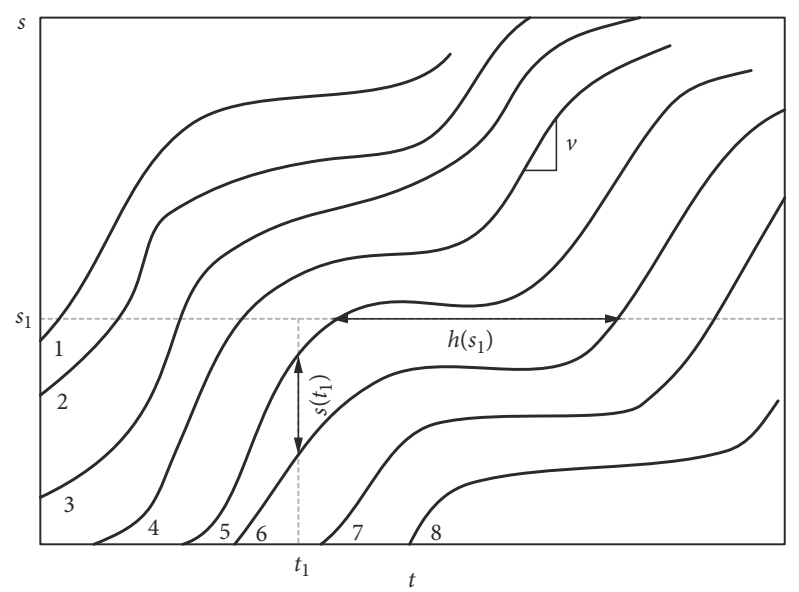

Figure 1. Representation of: a - platoon formation; $\mathrm{b}$ - time-space diagram under mixed traffic operations tion models have, therefore, been developed and tested for the purpose of modelling headways considering following and free vehicles separately. They are respectively Cowan's M1-M4 model (Cowan 1975), double displaced negative exponential distribution model (Zhang et al. 2007) and the generalized queuing model (Branston 1976). Among them, Cowan's M3 model has been widely applied for modelling headways because it is relatively simpler than other types of mixed models and gives more realistic results particularly while describing longer headways (Zhang, Wang 2014; Tanyel, Yayla 2003).

Most of the modelling approaches described in so far focused mixed vehicular flow. There have been a handful of studies that explored impact of vehicle types on headway distribution. Varied static and dynamic characteristics of vehicles have deviating impacts on traffic operations and safety. For instance, when a car approaches a large vehicle, like truck, car drivers take different car-following and lane changing decisions, which eventually results in different headway scenario (Peeta et al. 2005) and statistical tests on such data indicate the need of considering vehicle-type-specific headways separately (Dong et al. 2015). Interestingly, shifted negative exponential distribution (Ye, Zhang 2009) and inverse Gaussian distribution (Weng et al. 2014) were found to give a decent fit for Truck-Car and Truck-Truck headways whereas it was Erlang distribution (Ye, Zhang 2009) and lognormal distribution (Weng et al. 2014) when a car follows a truck.

A fairly recent study on Indian two-lane roads observed that at car-following state under mixed traffic, headway between two vehicles depends on the length of the lead vehicle (Penmetsa et al. 2015). Existence of NMV in the traffic has also an impact on distribution of headways (Saha et al. 2019). This fact along with the pressing need of developing capacity standards has been the motives of exploring the effect of leading and following vehicle types on headways under such traffic. On the basis of field data collected on two-lane rural roads in India, the paper analysed sixteen types of time headways derived from different combinations of vehicle types (leader-follower). Furthermore, distribution models were developed at different flow levels in order to examine the variations and the estimated probabilities of a few combinations were compared with those obtained from more or less homogeneous traffic.

\section{Objectives of the paper}

The premise on which the present paper is based considers data collected from two-lane roads where the prevalent traffic is mixed in character and composed of a wide variety of vehicle types in terms of their static and dynamic characteristics. They were classified into six types: car, Two-Wheeler (TW), bus, truck, three-wheeler and NMV. Since proportion of bus and three-wheelers was significantly low compared to the rest, the study considered four vehicle types and their sixteen combinations (leader-follower). Accordingly, the paper aimed at meeting the following objectives: 
- defining appropriate headway distributions for different leader-follower vehicle type combinations using Maximum Likelihood Estimation (MLE) and Kolmogorov-Smirnov (K-S) test technique;

- evaluating the impacts of traffic flow on different leader-follower combinations and understanding the car-following behaviour of different vehicle types;

- examining the impact of mixed traffic flow on headways by comparing the probabilities observed in the current study and those obtained from roads with more or less homogeneous traffic.

\section{Field data}

\subsection{Data collection}

Field study was conducted on a National Highway (twolane highway) in the North-East India, popularly known as the Assam-Agartala road (NH-8). A wide range of flow levels was covered while capturing traffic data. Further, pilot studies were conducted on two different highway segments, which have almost similar roadway and traffic characteristics for the purpose of verifying degree of accuracies in model estimates: they are Jaipur-Sikar road (NH-11) and Dankuni-Serampore road (SH-13) respectively in western and eastern part of the country. Study sites were selected in such a way so that they are free from the effect of intersection, curvature, ribbon development and also pavement conditions were good and uniform (Figure 2a). All the study segments traverse through plain terrain of rural areas (predominantly agricultural and industrial areas) and posted speeds on these roads were observed to be in the range of $50 \ldots 60 \mathrm{~km} / \mathrm{h}$. Further, Annual Average Daily Traffic (AADT) on the selected highway sections was also measured and found to be in the range of $15000 \ldots 17000 \mathrm{pc} /$ day: $17000 \mathrm{pc} /$ day on NH-8, $16000 \mathrm{pc} /$ day on SH-13 and $15000 \mathrm{pc} /$ day on $\mathrm{NH}-11$.

Video photographic survey technique was adopted while collecting field data. A reference line was marked on the pavement and two observation points were chosen for installing the video cameras; one in each direction, for

a)

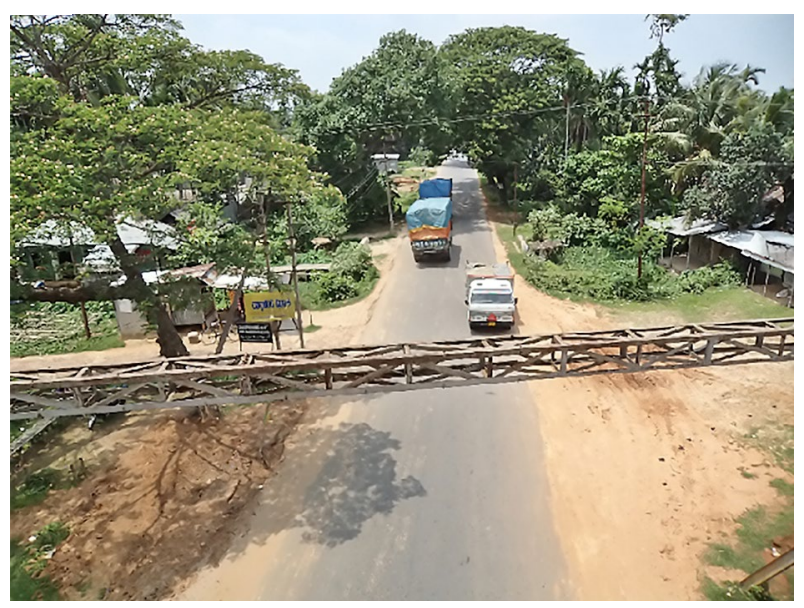

recording the time when front and rear ends of a vehicle cross the reference line. The directional traffic was termed as west and eastbound traffic respectively. Further, an attempt was made to capture heavy flow next to a bottleneck created by closing one lane of the two-lane carriageway and also, by stopping traffic movements for about two minutes to examine the discharged flow on the study section. The process was repeated for a number of times, so, as to ensure adequacy in sample size. Traffic police help was taken for conducting the study (Saha et al. 2019). The necessary readings, i.e. vehicle type, entry and exit time of front and rear ends of the vehicles were extracted from the video files and headways between successive vehicles were computed accordingly; in a way that the difference between the time when the front of a vehicle arrives at a point on the highway and the time the front of the next vehicle arrives at the same point was noted (in seconds).

Table 1 provides the details of vehicular count, data collection duration and observed vehicle types at different $v / c$ ratio derived based on a capacity value of $2300 \mathrm{pc} / \mathrm{h}$ (Saha et al. 2017b). The observed vehicles were classified into six types: car, TW, bus, truck, three-wheeler and NMV. Figure $2 \mathrm{~b}$ exhibits the proportion of these vehicle types in the traffic. Presence of TW was noticeable on all the three road sections and share of NMV and threewheelers was considerable on sections having frequent access points. Proportion of bus was, however, marginal on all the sections. Thus, the current study considered four vehicle types and sixteen combinations of leading-following vehicle pairs: TW-TW, TW-Truck, TW-Car, TWNMV, Truck-Truck, Truck-TW, Truck-Car, Truck-NMV, Car-Car, Car-TW, Car-Truck, Car-NMV, NMV-NMV, NMV-TW, NMV-Truck and NMV-Car. Vehicle-typespecific headways were then studied at different flow levels categorize as follows:

$-<400 \mathrm{veh} / \mathrm{h}$ : low traffic;

$-500 \ldots 700 \mathrm{veh} / \mathrm{h}$ : moderate to heavy traffic without significant slowing;

$-800 \ldots 1000 \mathrm{veh} / \mathrm{h}$ : heavy traffic involving slowing and stopping.

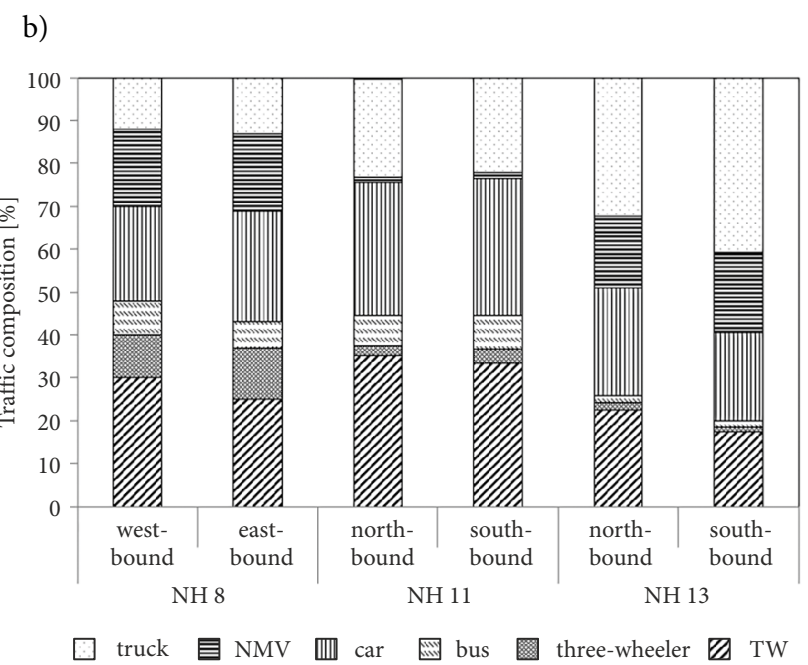

Figure 2. A view (a) of the study site (photo by author) and observed traffic compositions (b) at the study sites 
Table 1. Details of vehicular counts, data collection duration and vehicle types observed at the study sites

\begin{tabular}{|c|c|c|c|c|c|c|c|c|c|c|}
\hline \multirow{2}{*}{\multicolumn{2}{|c|}{ Details of traffic survey }} & \multicolumn{9}{|c|}{$v / c$ ratio } \\
\hline & & \multirow{2}{*}{$\begin{array}{c}0.2 \\
1916 \\
\end{array}$} & \multirow{2}{*}{$\begin{array}{c}0.3 \\
2222\end{array}$} & \multirow{2}{*}{$\frac{0.4}{2424}$} & \multirow{2}{*}{$\begin{array}{c}0.5 \\
1556\end{array}$} & \multirow{2}{*}{$\frac{0.6}{2040}$} & \multirow{2}{*}{$\begin{array}{c}0.7 \\
1962\end{array}$} & \multirow{2}{*}{$\begin{array}{c}0.8 \\
1276\end{array}$} & \multirow{2}{*}{$\begin{array}{l}0.9 \\
938\end{array}$} & \multirow{2}{*}{$\begin{array}{l}1.0 \\
944\end{array}$} \\
\hline Rond NH_R & Total vehicle count [veh] & & & & & & & & & \\
\hline Tau & Duration of data collection [min] & 225 & 190 & 190 & 85 & 95 & 80 & 45 & 30 & 30 \\
\hline \multirow{6}{*}{ Type of vehicles } & TW & $\checkmark$ & $\checkmark$ & $\checkmark$ & $\checkmark$ & $\checkmark$ & $\checkmark$ & $\checkmark$ & $\checkmark$ & $\checkmark$ \\
\hline & Three-wheeler & $\checkmark$ & $\checkmark$ & $\checkmark$ & $\checkmark$ & $\checkmark$ & $\checkmark$ & $\checkmark$ & $\checkmark$ & $\checkmark$ \\
\hline & Truck & $\checkmark$ & $\checkmark$ & $\checkmark$ & $\checkmark$ & $\checkmark$ & $\checkmark$ & $\checkmark$ & $\checkmark$ & $\checkmark$ \\
\hline & Car & $\checkmark$ & $\checkmark$ & $\checkmark$ & $\checkmark$ & $\checkmark$ & $\checkmark$ & $\checkmark$ & $\checkmark$ & $\checkmark$ \\
\hline & Bus & $\checkmark$ & $\checkmark$ & $\checkmark$ & $\checkmark$ & $\checkmark$ & $\checkmark$ & $\checkmark$ & $\checkmark$ & $\checkmark$ \\
\hline & NMV & $\times$ & $\checkmark$ & $\checkmark$ & $\checkmark$ & $\checkmark$ & $\checkmark$ & $\checkmark$ & $\checkmark$ & $\checkmark$ \\
\hline \multirow{2}{*}{ Road NH-11 } & Total vehicle count [veh] & 204 & 506 & 402 & - & - & - & - & - & - \\
\hline & Duration of data collection [min] & 25 & 45 & 20 & - & - & - & - & - & - \\
\hline \multirow{6}{*}{ Type of vehicles } & TW & $\checkmark$ & $\checkmark$ & $\checkmark$ & - & - & - & - & - & - \\
\hline & Three-wheeler & $\checkmark$ & $\checkmark$ & $\checkmark$ & - & - & - & - & - & - \\
\hline & Truck & $\checkmark$ & $\checkmark$ & $\checkmark$ & - & - & - & - & - & - \\
\hline & Car & $\checkmark$ & $\checkmark$ & $\checkmark$ & - & - & - & - & - & - \\
\hline & Bus & $\checkmark$ & $\checkmark$ & $\checkmark$ & - & - & - & - & - & - \\
\hline & NMV & $x$ & $x$ & $\checkmark$ & - & - & - & - & - & - \\
\hline \multirow{2}{*}{ Road SH-13 } & Total vehicle count [veh] & - & - & - & 1606 & 1495 & 807 & - & - & - \\
\hline & Duration of data collection [min] & - & - & - & 85 & 65 & 20 & - & - & - \\
\hline \multirow{6}{*}{ Type of vehicles } & TW & - & - & - & $\checkmark$ & $\checkmark$ & $\checkmark$ & - & - & - \\
\hline & Three-wheeler & - & - & - & $\checkmark$ & $\checkmark$ & $\checkmark$ & - & - & - \\
\hline & Truck & - & - & - & $\checkmark$ & $\checkmark$ & $\checkmark$ & - & - & - \\
\hline & Car & - & - & - & $\checkmark$ & $\checkmark$ & $\checkmark$ & - & - & - \\
\hline & Bus & - & - & - & $\checkmark$ & $\checkmark$ & $\checkmark$ & - & - & - \\
\hline & NMV & - & - & - & $\checkmark$ & $\checkmark$ & $\checkmark$ & - & - & - \\
\hline
\end{tabular}

Notes: $\checkmark$ present in traffic flow; $\times$ absent in traffic flow.

\subsection{Characteristics of the field data}

Combination of vehicle pairs was further grouped into four types on the basis of involvement of vehicle types. When the group was of only passenger vehicles like, car or TW, it was designated as "Headway type 1". By the same token, "Headway type 2-4" was identified when trucks and NMV are found in the group. Accordingly, histograms were plotted separately for each headway types with the aim of understanding the car-following behaviour (Figure 3). It was observed that a car or a TW usually follow each other keeping very short headways while taking overtaking decision. In case of Headway type 2, the characteristic of headways was rather exciting; a car follows a truck with widely spaced headways, whereas it was quite the opposite when a truck follows a car. This could be due to the psychological facts, which compel car drivers to keep wide space while following a heavy vehicle. However, motorvehicles were observed to keep shorter headways while following NMV ones and the probability of such headways reduces to a considerable extent when NMV are followers. This could be due to lower braking capabilities of such vehicles. Bike riders, on the other hand, always make at- tempts to overtake the lead vehicle irrespective of vehicle type and sometimes use the same lane to perform such overtaking resulting in higher probability shorter headways.

\subsection{Descriptive statistics of the headway data}

The fundamental statistical properties such as mean, standard deviation, Coefficient of Variation (CV) of sixteen vehicle pairs were calculated and presented in Table 2 . A look into the table reveals that mean and standard deviation of vehicle-type-specific headways are mostly decreasing with the flow rate. This is due to the fact that state of headway changes from random to constant with the increase of traffic flow resulting in frequent platooning and subsequent increase of shorter headways. It was also found that at almost all flow levels, headway is smallest for TW-TW combination whereas it was found to be largest in case of Truck-Truck combination. In addition, truck-followed mean headways were observed to be larger than the car-followed mean headway. This finding makes it evident that while following a truck drivers take more conservative attitude than that of a car because of the 
a)

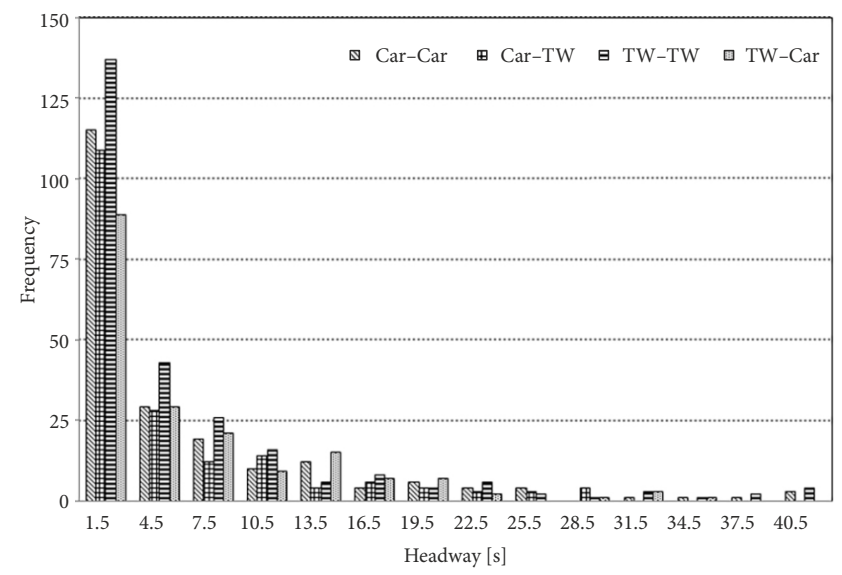

c)

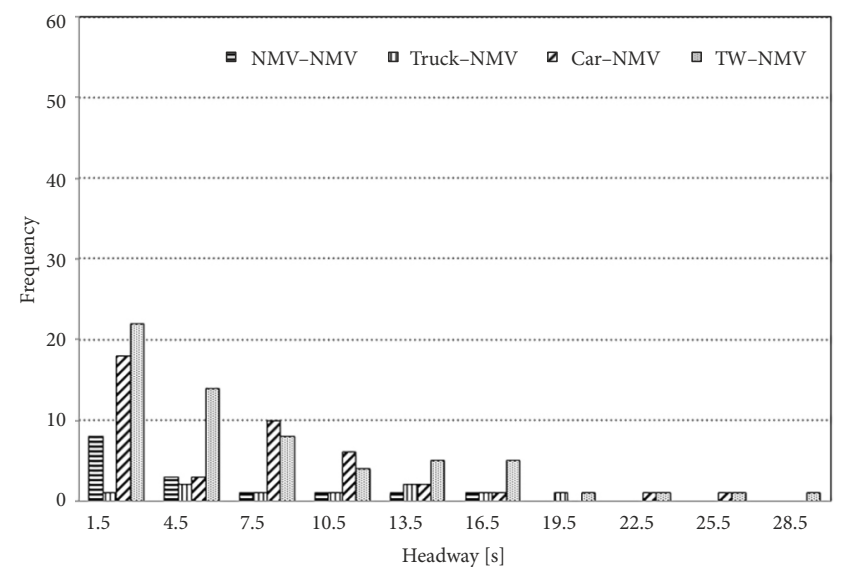

b)

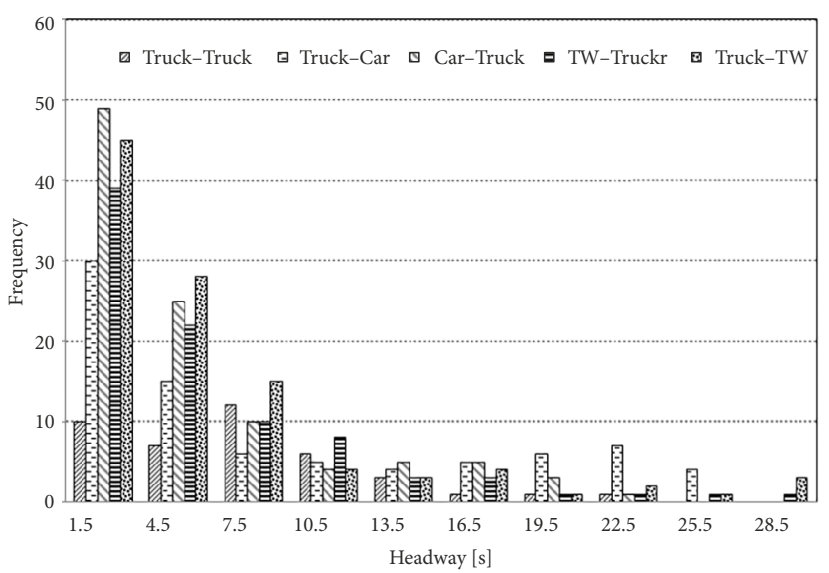

d)

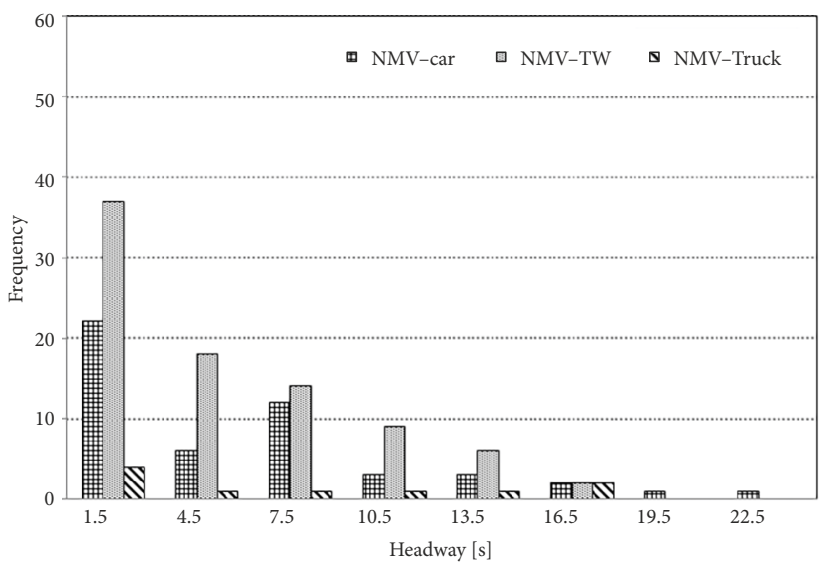

Figure 3. Histogram of four vehicle-type-specific headways: a - Headway type 1; b - Headway type 2; c - Headway type 3; d - Headway type 4

larger size of truck and lower braking capability. Notably, such truck-followed headways were observed to be much higher in the event of a truck following another truck; which however starts diminishing with the increase of flow. At heavy flow, they (Truck-Truck headways) were again observed to increase to a certain extent from those of moderate flow levels; this attributes to drastic speed drops of truck traffic and their stop-and-go movement at such flow level. Observations indicate that under mixed traffic TW do not follow lane discipline and move with very short headways to perform overtaking. Also, motorvehicles, by virtue of its dynamics, i.e. acceleration and braking, keep reasonably shorter headways while following NMV ones. Restrictions on overtaking in the event of traffic compression at high and congested flow level, however, result in an increase of headways; this is mainly due to the fact that absence of any vehicle warning or indicator lights in NMVs made car drivers little more cautious on roads. Thus, it is quite evident that characteristics of headways are dependent on the types of leader and follower vehicles. Similar results were also obtained by couple of international studies (Ye, Zhang 2009; Weng et al. 2014).

\section{Predictive models}

\subsection{Headway distribution models}

Negative exponential distribution is conventionally used to describe time headways. However, there have been a number of researchers who proposed the use of several other models while modelling time headways in the event of heterogeneity in traffic mix. Lognormal distribution is found effective especially under car-following situation (Greenberg 1966). Gamma (Zhang et al. 2007; Abtahi et al. 2011), Erlang (Al-Ghamdi 2001) and Weibull (Weng et al. 2014; Yin et al. 2009) distributions are widely used as headway model because of their flexibility and compatibility. The paper, therefore, considered these five distributions for the purpose of modelling headways at different flow levels: low, moderate and heavy flow of traffic. Equations (1)-(5) demonstrates the probability density functions of the selected distributions, which were used at the time of experiment:

Negative exponential distribution:

$$
f(h)=\lambda \cdot \exp (-\lambda \cdot h)
$$


Table 2. Descriptive statistics of vehicle-type-specific headways

\begin{tabular}{|c|c|c|c|c|c|c|}
\hline \multirow[t]{2}{*}{ Headway type } & Mean [s] & $\begin{array}{c}\text { Standard } \\
\text { deviation [s] }\end{array}$ & $\mathrm{CV}$ & Mean [s] & $\begin{array}{c}\text { Standard } \\
\text { deviation [s] }\end{array}$ & $\mathrm{CV}$ \\
\hline & \multicolumn{3}{|c|}{ Westbound traffic } & \multicolumn{3}{|c|}{ Eastbound traffic } \\
\hline \multicolumn{7}{|c|}{ Low traffic flow level (<400 veh/h) } \\
\hline TW-TW & 1.33 & 0.82 & 0.62 & 1.52 & 0.84 & 0.55 \\
\hline Truck-Truck & 12.37 & 18.46 & 1.49 & 13.13 & 14.50 & 1.10 \\
\hline Car-Car & 4.93 & 6.71 & 1.36 & 8.05 & 10.22 & 1.27 \\
\hline TW-NMV & 3.71 & 2.49 & 0.67 & 1.25 & 1.22 & 1.03 \\
\hline TW-Truck & 2.01 & 2.17 & 1.08 & 3.67 & 4.03 & 1.10 \\
\hline TW-Car & 3.42 & 3.15 & 0.92 & 3.25 & 3.49 & 1.08 \\
\hline Car-NMV & 8.92 & 6.76 & 0.76 & 9.72 & 9.08 & 0.93 \\
\hline Car-TW & 2.80 & 1.87 & 0.67 & 3.10 & 2.47 & 0.80 \\
\hline Truck-NMV & 2.56 & 3.21 & 1.25 & 2.29 & 3.49 & 1.53 \\
\hline Truck-TW & 1.58 & 1.21 & 0.76 & 3.20 & 2.74 & 0.86 \\
\hline NMV-Truck & 2.44 & 1.88 & 0.77 & 1.83 & 1.75 & 0.96 \\
\hline NMV-NMV & 8.67 & 9.82 & 1.13 & 9.50 & 8.04 & 0.85 \\
\hline NMV-TW & 1.61 & 0.70 & 0.44 & 1.57 & 1.40 & 0.89 \\
\hline NMV-Car & 1.75 & 1.17 & 0.67 & 1.50 & 1.20 & 0.80 \\
\hline Truck-Car & 5.60 & 3.05 & 0.54 & 5.25 & 6.90 & 1.31 \\
\hline Car-Truck & 4.33 & 4.44 & 1.03 & 4.67 & 3.32 & 0.71 \\
\hline \multicolumn{7}{|c|}{ Moderate traffic flow level $(500 \ldots 700 \mathrm{veh} / \mathrm{h})$} \\
\hline TW-TW & 0.67 & 0.82 & 1.22 & 0.86 & 0.69 & 0.81 \\
\hline Truck-Truck & 9.38 & 11.98 & 1.28 & 8.50 & 12.87 & 1.51 \\
\hline Car-Car & 3.29 & 4.46 & 1.36 & 6.43 & 9.40 & 1.46 \\
\hline TW-NMV & 3.14 & 2.79 & 0.89 & 3.56 & 3.43 & 0.97 \\
\hline TW-Truck & 5.25 & 3.85 & 0.73 & 4.38 & 5.45 & 1.25 \\
\hline TW-Car & 4.08 & 6.03 & 1.48 & 3.63 & 4.11 & 1.13 \\
\hline Car-NMV & 4.71 & 5.68 & 1.20 & 5.62 & 5.18 & 0.92 \\
\hline Car-TW & 7.42 & 8.40 & 1.13 & 8.72 & 7.91 & 0.91 \\
\hline Truck-NMV & 1.03 & 1.51 & 1.46 & 1.86 & 1.38 & 0.74 \\
\hline Truck-TW & 4.29 & 4.99 & 1.16 & 4.02 & 5.86 & 1.46 \\
\hline NMV-Truck & 2.33 & 2.07 & 0.89 & 1.29 & 1.38 & 1.07 \\
\hline NMV-NMV & 7.83 & 7.36 & 0.94 & 8.33 & 8.97 & 1.08 \\
\hline NMV-TW & 3.62 & 5.11 & 1.41 & 3.29 & 3.77 & 1.15 \\
\hline NMV-Car & 2.32 & 2.24 & 0.96 & 2.57 & 1.62 & 0.63 \\
\hline Truck-Car & 5.33 & 9.61 & 1.15 & 5.43 & 9.25 & 1.70 \\
\hline Car-Truck & 4.83 & 7.41 & 1.53 & 3.71 & 2.43 & 0.65 \\
\hline \multicolumn{7}{|c|}{ Heavy traffic flow level $(800 \ldots 1000 \mathrm{veh} / \mathrm{h})$} \\
\hline TW-TW & 1.14 & 1.49 & 1.30 & 1.83 & 1.47 & 0.80 \\
\hline Truck-Truck & 10.88 & 19.35 & 1.78 & 10.25 & 15.89 & 1.55 \\
\hline Car-Car & 1.83 & 0.75 & 0.41 & 2.83 & 1.47 & 0.52 \\
\hline TW-NMV & 9.67 & 11.88 & 1.23 & 10.17 & 11.05 & 1.09 \\
\hline TW-Truck & 4.14 & 5.49 & 1.33 & 5.43 & 7.21 & 1.33 \\
\hline TW-Car & 5.43 & 6.50 & 1.20 & 6.57 & 6.89 & 1.05 \\
\hline Car-NMV & 6.33 & 9.33 & 1.47 & 7.83 & 10.70 & 1.37 \\
\hline Car-TW & 8.75 & 7.77 & 0.89 & 9.40 & 8.60 & 0.92 \\
\hline Truck-NMV & 1.17 & 1.28 & 1.10 & 1.33 & 1.03 & 0.77 \\
\hline Truck-TW & 2.67 & 3.88 & 1.46 & 3.33 & 4.63 & 1.39 \\
\hline NMV-Truck & 1.23 & 1.41 & 1.15 & 2.08 & 1.79 & 0.86 \\
\hline NMV-NMV & 9.50 & 11.61 & 1.22 & 12.15 & 14.75 & 1.21 \\
\hline NMV-TW & 3.75 & 4.28 & 1.14 & 3.17 & 3.51 & 1.11 \\
\hline NMV-Car & 2.25 & 1.89 & 0.84 & 2.46 & 1.92 & 0.78 \\
\hline Truck-Car & 5.16 & 5.02 & 0.97 & 6.04 & 5.62 & 0.93 \\
\hline Car-Truck & 3.33 & 4.32 & 1.30 & 4.17 & 5.04 & 1.21 \\
\hline
\end{tabular}


Erlang distribution:

$$
f(h)=\frac{h^{m-1}}{\beta^{m} \cdot \Gamma(m) \cdot \exp \left(-\frac{h}{\beta}\right)},
$$

Lognormal distribution:

$$
f(h)=\frac{1}{h \cdot \sigma \cdot \sqrt{2 \cdot \pi}} \cdot \exp \left(-\frac{(\ln h-\mu)^{2}}{2 \cdot \sigma^{2}}\right),
$$

Gamma distribution:

$$
f(h)=\frac{h^{\alpha-1}}{\beta^{\alpha} \cdot \Gamma(\alpha)} \cdot \exp \left(-\frac{h}{\beta}\right),
$$

Weibull distribution:

$$
f(h)=\frac{\alpha}{\beta} \cdot\left(\frac{h}{\beta}\right)^{(\alpha-1)} \cdot \exp \left(-\left(\frac{h}{\beta}\right)^{\alpha}\right),
$$

where: $f(h)$ - probability density function; $h$ - time headway of vehicles; $\lambda$ - continuous scale parameter $(\lambda>0)$; $m$ - shape parameter (positive integer); $\beta$ - continuous scale parameter (Erlang distribution) $(\beta>0) ; \Gamma-$ Gamma function; $\sigma$ - continuous scale parameter (Lognormal distribution) $(\sigma>0) ; \mu$ - continuous location parameter; $\alpha$ - continuous shape parameter $(\alpha>0)$.

\subsection{Model goodness-of-fit and parameter estimation}

An attempt was made to fit the distribution function to field data and obtain a calibrated expression. There are several methods to estimate the parameters: MLE (Myung 2003), method of moments (Wang, Peng 2014), minimum chi-square method (Kominek 2002) and simultaneous numerical estimation (Vasconcelos et al. 2012). The MLE is, however, considered to be effective especially when the sample size is not large (Luttinen 1999). Since the current study is based on field data, MLE was applied as an effective heuristic method. Thus, the parameters were estimated for the field data collected at study site by maximizing the log-likelihood function (Equations (6) and (7)):

$$
\begin{aligned}
& L(\hat{\theta})=\prod_{i=1}^{n} f\left(h_{i} \mid \hat{\theta}\right) ; \\
& \ln L(\hat{\theta})=\sum_{i=1}^{n} \ln f\left(h_{i} \mid \hat{\theta}\right),
\end{aligned}
$$

where: $L(\hat{\theta})$ - likelihood function; $\hat{\theta}$ - parameter vector; $f\left(h_{i} \mid \hat{\theta}\right)$ - probability density function.

In this paper, $\mathrm{K}-\mathrm{S}$ test (Ye, Zhang 2009) is chosen to measure goodness-of-fit of the selected headway models to the observed headway data. The K-S test statistic was computed at the desired significance level $\alpha$ for the selected distributions and the distribution, which is expected to give the smallest statistic value was considered as the best fitted model. The null hypotheses for each test were as follows: "the compatibility hypothesis of headway distribution with fitted model was rejected $(P$-value $<\alpha)$ or not rejected $(P$-value $>\alpha)$ ". Table 3 provides the goodness-offit details of the selected distributions for different vehicle type combinations and the parameters of the best fitted models are displayed in Table 4.

As anticipated, distributions differ across headway types and flow levels. This could be due to changing carfollowing behaviour and also, regular interactions of vehicles at increased flow levels. Figures 4-6 contemplates the distributions for low to heavy flow of traffic. It was observed that in case of Truck-Truck and NMV-Motor-vehicle combinations, probability of widely spaced headways is small even at low and moderate flow. This explicates two key operational characteristics of mixed traffic: truck drivers prefer to move in a group and impedance caused by NMV is the primarily cause of platooning under low flow. However, at heavy flow, such probabilities were observed to be relatively high; this attributes to driver's alertness about the low braking capabilities of truck and NMV.

\section{Results analysis}

Drivers' behaviour in choosing headways depends on type of vehicle combinations and under mixed traffic conditions it varies significantly. For instance, they usually exhibit conservative attitude in the event of TruckCar combination and act differently than that of the case of following a car. Current investigations on mixed traffic found different vehicle-type-specific combinations to have different headway characteristics and, accordingly, applied appropriate distribution function while describing them. Subsequent to the determination of appropriate distributions and parameters, probabilities of vehicle-specific headways were calculated using the predictive models for different flow levels (Table 5).

As anticipated, for almost all vehicle type combinations probability of short headways increases with the flow except the case when a car follows another. Field observations indicate that since speed potential of car is relatively higher compared to other vehicles sharing the same road space, car drivers frequently participate in overtaking operations and move with short headways while performing it. However, limited passing or overtaking opportunities at increased flow level restrict them from taking such initiatives.

Notably, probability of shorter headways was reasonably high even at low flow when TW are followers. Mostly bike riders are reluctant to obey lane discipline under mixed traffic and they sometimes try to move in parallel with other vehicles on the same lane expecting that overtaking will be easy. This eventually results in short headways even when the flow is not high. Probability of such short headways, however, starts decreasing with the increase of flow because of limited passing opportunities and they start keeping reasonably safe distance especially when they follow a heavy vehicle or truck. NMV, on the other hand, were observed to keep short headways at such flow while following a motorised one because of their low speed potential; stopping sight distance requirements is very small for such vehicles. 
Table 3. Goodness-of-fit test results for the selected distribution models

\begin{tabular}{|c|c|c|c|c|c|c|c|c|}
\hline \multirow[b]{2}{*}{ Headway type } & \multicolumn{5}{|c|}{$\mathrm{K}-\mathrm{S}$ statistic value } & \multirow[b]{2}{*}{$P$-value } & \multirow[b]{2}{*}{$\alpha$} & \multirow{2}{*}{$\begin{array}{c}\text { Hypothesis } \\
\text { test }\end{array}$} \\
\hline & Exponential & Erlang & $\begin{array}{c}\text { Log- } \\
\text { normal }\end{array}$ & Gamma & Weibull & & & \\
\hline \multicolumn{9}{|c|}{ Westbound traffic } \\
\hline \multicolumn{9}{|c|}{ Low traffic flow level $(<400 \mathrm{veh} / \mathrm{h})$} \\
\hline TW-TW & 0.2021 & 0.1891 & 0.1784 & 0.13161 & 0.1595 & 0.9424 & 0.05 & not reject \\
\hline Truck-Truck & 0.2648 & no fit & 0.3326 & 0.2833 & 0.2500 & 0.5439 & 0.05 & not reject \\
\hline Car-Car & 0.1735 & no fit & 0.2548 & 0.2204 & 0.1918 & 0.7317 & 0.05 & not reject \\
\hline TW-NMV & 0.5000 & no fit & 0.5915 & 0.5593 & no fit & 0.0077 & 0.05 & reject \\
\hline TW-Truck & 0.2732 & no fit & 0.4751 & 0.2501 & 0.2931 & 0.3779 & 0.05 & not reject \\
\hline TW-Car & 0.1931 & 0.1886 & 0.1978 & 0.1658 & 0.1909 & 0.8442 & 0.05 & not reject \\
\hline Car-NMV & 0.2935 & 0.3361 & 0.3959 & 0.2535 & 0.3239 & 0.4669 & 0.05 & not reject \\
\hline Car-TW & 0.3003 & 0.1903 & 0.2023 & 0.1589 & 0.1815 & 0.9294 & 00.5 & not reject \\
\hline Truck-NMV & 0.2317 & no fit & 0.3897 & 0.2222 & 0.2890 & 0.6873 & 0.05 & not reject \\
\hline Truck-TW & 0.3114 & no fit & 0.3321 & 0.2583 & 0.2258 & 0.3676 & 0.05 & not reject \\
\hline NMV-Truck & 0.7778 & no fit & no fit & 0.7578 & 0.5253 & 0.4533 & 0.05 & not reject \\
\hline NMV-NMV & 0.5000 & no fit & 0.5935 & 0.5943 & no fit & 0.0655 & 0.05 & not reject \\
\hline NMV-TW & 0.6333 & no fit & no fit & 0.8333 & no fit & 0.0943 & 0.05 & not reject \\
\hline NMV-Car & 0.6482 & no fit & 0.6560 & 0.6950 & 0.6250 & 0.0015 & 0.05 & reject \\
\hline Truck-Car & 0.1885 & 0.3040 & 0.1629 & 0.1316 & 0.1639 & 0.9424 & 0.05 & not reject \\
\hline Car-Truck & 0.3003 & 0.2995 & 0.2417 & 0.2216 & 0.2495 & 0.9207 & 0.05 & not reject \\
\hline \multicolumn{9}{|c|}{ Moderate traffic flow level $(500 \ldots 700 \mathrm{veh} / \mathrm{h})$} \\
\hline TW-TW & 0.1921 & no fit & 0.1356 & 0.3058 & 0.1917 & 0.9933 & 0.05 & not reject \\
\hline Truck-Truck & 0.2423 & no fit & 0.2756 & 0.2192 & 0.3078 & 0.8809 & 0.05 & not reject \\
\hline Car-Car & 0.1977 & no fit & 0.1882 & 0.2132 & 0.2469 & 0.9559 & 0.05 & not reject \\
\hline TW-NMV & 0.2236 & no fit & 0.2223 & 0.1967 & 0.2416 & 0.9394 & 0.05 & not reject \\
\hline TW-Truck & 0.3168 & no fit & 0.2465 & 0.2085 & 0.2018 & 0.8404 & 0.05 & not reject \\
\hline TW-Car & 0.1372 & no fit & 0.1421 & 0.1339 & 0.1461 & 0.9975 & 0.05 & not reject \\
\hline Car-NMV & 0.2374 & no fit & 0.2768 & 0.2763 & 0.2701 & 0.7464 & 0.05 & not reject \\
\hline Car-TW & 0.2533 & no fit & 0.2229 & 0.2097 & 0.2328 & 0.8689 & 0.05 & not reject \\
\hline Truck-NMV & 0.3333 & no fit & 0.4838 & 0.4779 & 0.3963 & 0.4234 & 0.05 & not reject \\
\hline Truck-TW & 0.2531 & no fit & 0.2961 & 0.2255 & 0.2703 & 0.7984 & 0.05 & not reject \\
\hline NMV-Truck & 0.5000 & no fit & 0.5942 & 0.5943 & no fit & 0.9865 & 0.05 & not reject \\
\hline NMV-NMV & 0.1431 & 0.1804 & 0.1583 & 0.1473 & 0.1809 & 0.9979 & 0.05 & not reject \\
\hline NMV-TW & 0.1535 & no fit & 0.1814 & 0.1611 & 0.2146 & 0.9787 & 0.05 & not reject \\
\hline NMV-Car & 0.3935 & no fit & 0.4236 & 0.3926 & 0.4249 & 0.1016 & 0.05 & not reject \\
\hline Truck-Car & 0.2584 & no fit & 0.3019 & 0.2575 & 0.2918 & 0.6535 & 0.05 & not reject \\
\hline Car-Truck & 0.1919 & 0.2209 & 0.2719 & 0.1851 & 0.2782 & 0.9186 & 0.05 & not reject \\
\hline \multicolumn{9}{|c|}{ Heavy traffic flow level $(800 \ldots 1000 \mathrm{veh} / \mathrm{h})$} \\
\hline TW-TW & 0.3616 & no fit & 0.1863 & 0.2703 & 0.1716 & 0.9422 & 0.05 & not reject \\
\hline Truck-Truck & 0.4089 & 0.2774 & 0.2706 & 0.2582 & 0.3421 & 0.7358 & 0.05 & not reject \\
\hline Car-Car & 0.3413 & no fit & 0.2334 & 0.3961 & 0.2809 & 0.7646 & 0.05 & not reject \\
\hline TW-NMV & 0.2628 & no fit & 0.1745 & 0.1884 & 0.2115 & 0.9761 & 0.05 & not reject \\
\hline TW-Truck & 0.3569 & no fit & 0.3880 & 0.2260 & 0.3283 & 0.7965 & 0.05 & not reject \\
\hline TW-Car & 0.3685 & no fit & 0.2358 & 0.2193 & 0.2996 & 0.4675 & 0.05 & not reject \\
\hline Car-NMV & 0.2893 & no fit & 0.1792 & 0.3300 & 0.2513 & 0.9701 & 0.05 & not reject \\
\hline Car-TW & 0.3814 & no fit & 0.2144 & 0.3628 & 0.1945 & 0.8701 & 0.05 & not reject \\
\hline Truck-NMV & 0.3333 & no fit & 0.4962 & 0.4932 & 0.4806 & 0.4234 & 0.05 & not reject \\
\hline Truck-TW & 0.3539 & no fit & 0.4939 & 0.4872 & 0.4757 & 0.3539 & 0.05 & not reject \\
\hline NMV-Truck & 0.3609 & 0.5468 & 0.4501 & 0.2982 & 0.3588 & 0.5628 & 0.05 & not reject \\
\hline NMV-NMV & 0.1774 & 0.3008 & 0.2321 & 0.2002 & 0.2186 & 0.8381 & 0.05 & not reject \\
\hline NMV-TW & 0.1627 & no fit & 0.2577 & 0.2224 & 0.2421 & 0.7377 & 0.05 & not reject \\
\hline NMV-Car & 0.2525 & no fit & 0.2095 & 0.1829 & 0.1813 & 0.7633 & 0.05 & not reject \\
\hline Truck-Car & 0.3763 & no fit & 0.2869 & 0.2592 & 0.3123 & 0.2864 & 0.05 & not reject \\
\hline Car-Truck & 0.4204 & 0.4397 & 0.3248 & 0.3040 & 0.3368 & 0.5379 & 0.05 & not reject \\
\hline
\end{tabular}


End of Table 3

\begin{tabular}{|c|c|c|c|c|c|c|c|c|}
\hline \multirow[b]{2}{*}{ Headway type } & \multicolumn{5}{|c|}{$\mathrm{K}-\mathrm{S}$ statistic value } & \multirow[b]{2}{*}{$P$-value } & \multirow[b]{2}{*}{$\alpha$} & \multirow{2}{*}{$\begin{array}{l}\text { Hypothesis } \\
\text { test }\end{array}$} \\
\hline & Exponential & Erlang & $\begin{array}{c}\text { Log- } \\
\text { normal }\end{array}$ & Gamma & Weibull & & & \\
\hline \multicolumn{9}{|c|}{ Eastbound traffic } \\
\hline \multicolumn{9}{|c|}{ Low traffic flow level $(<400 \mathrm{veh} / \mathrm{h})$} \\
\hline TW-TW & 0.2034 & 0.3033 & 0.1763 & 0.1427 & 0.1677 & 0.9694 & 0.05 & not reject \\
\hline Truck-Truck & 0.2525 & no fit & 0.2671 & 0.1719 & 0.1473 & 0.6016 & 0.05 & not reject \\
\hline Car-Car & 0.3065 & no fit & 0.3099 & 0.3343 & 0.2526 & 0.4707 & 0.05 & not reject \\
\hline TW-NMV & 0.3751 & no fit & 0.5037 & 0.5007 & 0.5018 & 0.1615 & 0.05 & not reject \\
\hline TW-Truck & 0.2222 & no fit & 0.3495 & 0.3344 & 0.2673 & 0.6873 & 0.05 & not reject \\
\hline TW-Car & 0.3219 & no fit & 0.2589 & 0.3846 & 0.4329 & 0.5284 & 0.05 & not reject \\
\hline Car-NMV & 0.1916 & 0.2242 & 0.2214 & 0.1646 & 0.1636 & 0.9136 & 0.05 & not reject \\
\hline Car-TW & 0.2757 & 0.3984 & 0.3324 & 0.3187 & 0.2545 & 0.3641 & 0.05 & not reject \\
\hline Truck-NMV & 0.7143 & no fit & no fit & 0.5983 & no fit & 0.6295 & 0.05 & not reject \\
\hline Truck-TW & 0.2684 & 0.3469 & 0.1878 & 0.2027 & 0.1851 & 0.8236 & 0.05 & not reject \\
\hline NMV-Truck & 0.3654 & 0.5306 & 0.5515 & 0.3611 & no fit & 0.3312 & 0.05 & not reject \\
\hline NMV-NMV & 0.6667 & no fit & 0.6746 & 0.6747 & no fit & 0.0037 & 0.05 & not reject \\
\hline NMV-TW & 0.2857 & 0.3392 & 0.4611 & 0.4607 & 0.4766 & 0.2525 & 0.05 & not reject \\
\hline NMV-Car & 0.2500 & 0.3648 & 0.4061 & 0.4014 & 0.2731 & 0.6134 & 0.05 & not reject \\
\hline Truck-Car & 0.3418 & no fit & 0.2809 & 0.3099 & 0.3177 & 0.4706 & 0.05 & not reject \\
\hline Car-Truck & 0.3485 & 0.5719 & 0.2319 & 0.2137 & 0.2014 & 0.7914 & 0.05 & not reject \\
\hline \multicolumn{9}{|c|}{ Moderate traffic flow level $(500 \ldots 700 \mathrm{veh} / \mathrm{h})$} \\
\hline TW-TW & 0.3276 & no fit & 0.2168 & 0.3044 & 0.2029 & 0.8366 & 0.05 & not reject \\
\hline Truck-Truck & 0.3082 & no fit & 0.4877 & 0.2997 & 0.2857 & 0.4337 & 0.05 & not reject \\
\hline Car-Car & 0.2897 & no fit & 0.3369 & 0.3763 & 03493 & 0.5086 & 0.05 & not reject \\
\hline TW-NMV & 0.2360 & 0.2874 & 0.2359 & 0.2067 & 0.2211 & 0.8717 & 0.05 & not reject \\
\hline TW-Truck & 0.2957 & no fit & 0.3303 & 0.1943 & 0.3041 & 0.8709 & 0.05 & not reject \\
\hline TW-Car & 0.3178 & no fit & 0.3461 & 0.3135 & 0.3569 & 0.2033 & 0.05 & not reject \\
\hline Car-NMV & 0.2043 & no fit & 0.2288 & 0.2155 & 0.2095 & 0.8902 & 0.05 & not reject \\
\hline Car-TW & 0.3843 & no fit & 0.2266 & 0.3663 & 0.1899 & 0.8443 & 0.05 & not reject \\
\hline Truck-NMV & 0.5457 & 0.5721 & no fit & 0.4943 & no fit & 0.0421 & 0.05 & reject \\
\hline Truck-TW & 0.4038 & no fit & 0.4409 & 0.2513 & 0.3017 & 0.6134 & 0.05 & not reject \\
\hline NMV-Truck & 0.3931 & 0.5489 & 0.5486 & 0.4028 & no fit & 0.1539 & 0.05 & not reject \\
\hline NMV-NMV & 0.3108 & 04531 & 0.3485 & 0.4943 & no fit & 0.3715 & 0.05 & not reject \\
\hline NMV-TW & 0.2473 & no fit & 0.3948 & 0.3090 & 0.3269 & 0.4303 & 0.05 & not reject \\
\hline NMV-Car & 0.3977 & 0.4412 & 0.3057 & 0.2904 & 0.3593 & 0.5055 & 0.05 & not reject \\
\hline Truck-Car & 0.3041 & no fit & 0.2361 & 0.3237 & 0.2344 & 0.7599 & 0.05 & not reject \\
\hline Car-Truck & 0.2452 & 0.2606 & 0.2861 & 0.2485 & 0.2325 & 0.6325 & 0.05 & not reject \\
\hline \multicolumn{9}{|c|}{ Heavy traffic flow level $(800 \ldots 1000 \mathrm{veh} / \mathrm{h})$} \\
\hline TW-TW & 0.3864 & no fit & 0.1795 & 0.3072 & 0.1709 & 0.9438 & 0.05 & not reject \\
\hline Truck-Truck & 0.3397 & 0.3187 & 0.1716 & 0.1754 & 0.2579 & 0.9795 & 0.05 & not reject \\
\hline Car-Car & 0.3799 & no fit & 0.2407 & 0.3815 & 0.2922 & 0.7315 & 0.05 & not reject \\
\hline TW-NMV & 0.2209 & no fit & 0.1751 & 0.1936 & 0.2045 & 0.9754 & 0.05 & not reject \\
\hline TW-Truck & 0.2897 & no fit & 0.2929 & 0.1927 & 0.2800 & 0.9163 & 0.05 & not reject \\
\hline TW-Car & 0.3374 & no fit & 0.2260 & 0.2141 & 0.2737 & 0.5781 & 0.05 & not reject \\
\hline Car-NMV & 0.2135 & no fit & 0.2083 & 0.2614 & 0.2357 & 0.9118 & 0.05 & not reject \\
\hline Car-TW & 0.3069 & no fit & 0.1705 & 0.2938 & 0.1898 & 09448 & 0.05 & not reject \\
\hline Truck-NMV & 0.4986 & 0.3609 & 0.4501 & 0.2982 & 0.3588 & 0.5629 & 0.05 & not reject \\
\hline Truck-TW & 0.3333 & no fit & 0.3991 & 0.3992 & 0.3936 & 0.4234 & 0.05 & not reject \\
\hline NMV-Truck & 0.2268 & 0.2981 & 0.3611 & 0.1852 & 0.3105 & 0.9611 & 0.05 & not reject \\
\hline NMV-NMV & 0.1739 & no fit & 0.2298 & 0.2534 & 0.2327 & 0.7556 & 0.05 & not reject \\
\hline NMV-TW & 0.1657 & no fit & 0.2382 & 0.2048 & 0.2566 & 0.8155 & 0.05 & not reject \\
\hline NMV-Car & 0.2333 & 0.1987 & 0.2358 & 0.2055 & 0.1798 & 0.8335 & 0.05 & not reject \\
\hline Truck-Car & 0.2845 & no fit & 0.2706 & 0.2638 & 0.3003 & 0.5535 & 0.05 & not reject \\
\hline Car-Truck & 0.3396 & 0.3187 & 0.1755 & 0.1716 & 0.2579 & 0.9751 & 0.05 & not reject \\
\hline
\end{tabular}

Note: bold values indicate smallest value of $\mathrm{K}-\mathrm{S}$ test statistic. 
Table 4. Parameters of distribution models

\begin{tabular}{|c|c|c|c|c|}
\hline \multirow[b]{2}{*}{ Headway type } & \multirow[b]{2}{*}{ Selected distribution } & \multicolumn{3}{|c|}{ Parameter } \\
\hline & & $\begin{array}{l}\text { Low traffic flow level } \\
(<400 \mathrm{veh} / \mathrm{h})\end{array}$ & $\begin{array}{c}\text { Moderate traffic flow level } \\
(500 \ldots 700 \mathrm{veh} / \mathrm{h})\end{array}$ & $\begin{array}{c}\text { Heavy traffic flow level } \\
(800 \ldots 1000 \mathrm{veh} / \mathrm{h})\end{array}$ \\
\hline \multicolumn{5}{|c|}{ Westbound traffic } \\
\hline TW-TW & Gamma/Lognormal/Weibull & $\begin{array}{l}\alpha=2.2181 \\
\beta=1.6746\end{array}$ & $\begin{array}{l}\sigma=0.9199 \\
\mu=1.7501\end{array}$ & $\begin{array}{l}\alpha=0.7393 \\
\beta=9.5665\end{array}$ \\
\hline Truck-Truck & Weibull/Gamma & $\begin{array}{l}\alpha=0.3833 \\
\beta=2.3290\end{array}$ & $\begin{array}{l}\alpha=1.2760 \\
\beta=1.8286\end{array}$ & $\begin{aligned} \alpha & =5.1042 \\
\beta & =0.4571\end{aligned}$ \\
\hline Car-Car & Exponential/Lognormal & $\lambda=0.2029$ & $\begin{array}{l}\sigma=1.0340 \\
\mu=1.6060\end{array}$ & $\begin{array}{l}\sigma=1.1777 \\
\mu=1.7048\end{array}$ \\
\hline TW-NMV & Exponential/Gamma/Lognormal & $\lambda=1.6667$ & $\begin{array}{l}\alpha=0.8495 \\
\beta=8.0439\end{array}$ & $\begin{aligned} \sigma & =1.1534 \\
\mu & =1.6323\end{aligned}$ \\
\hline TW-Truck & Gamma/Weibull & $\begin{aligned} \alpha & =0.8462 \\
\beta & =2.3636\end{aligned}$ & $\begin{array}{l}\alpha=2.1082 \\
\beta=4.6559\end{array}$ & $\begin{array}{l}\alpha=0.9739 \\
\beta=4.9627\end{array}$ \\
\hline TW-Car & Gamma & $\begin{array}{l}\alpha=1.1790 \\
\beta=2.2898\end{array}$ & $\begin{array}{l}\alpha=0.8364 \\
\beta=13.152\end{array}$ & $\begin{array}{l}\alpha=0.4227 \\
\beta=22.303\end{array}$ \\
\hline Car-NMV & Gamma/Exponential/Lognormal & $\begin{array}{l}\alpha=1.2857 \\
\beta=1.5556\end{array}$ & $\lambda=0.2121$ & $\begin{array}{l}\sigma=1.1215 \\
\mu=1.1337\end{array}$ \\
\hline Car-TW & Gamma/Lognormal/Weibull & $\begin{array}{l}\alpha=2.2329 \\
\beta=1.2540\end{array}$ & $\begin{array}{l}\sigma=1.3581 \\
\mu=1.6631\end{array}$ & $\begin{aligned} \alpha & =1.1426 \\
\beta & =4.7385\end{aligned}$ \\
\hline Truck-NMV & Gamma/Exponential & $\begin{array}{l}\alpha=1.4788 \\
\beta=2.2219\end{array}$ & $\lambda=0.75$ & $\lambda=0.8571$ \\
\hline Truck-TW & Weibull/Gamma/Exponential & $\begin{array}{l}\alpha=0.6819 \\
\beta=1.6324\end{array}$ & $\begin{array}{l}\alpha=0.7375 \\
\beta=5.8111\end{array}$ & $\lambda=0.3750$ \\
\hline NMV-Truck & Weibull/Exponential/Gamma & $\begin{array}{c}\alpha=1.1357 \\
\beta=1\end{array}$ & $\lambda=1.5$ & $\begin{array}{c}\alpha=1.6667 \\
\beta=0.8\end{array}$ \\
\hline NMV-NMV & Exponential & $\lambda=1.5$ & $\lambda=0.1276$ & $\lambda=0.1111$ \\
\hline NMV-TW & Exponential & $\lambda=3$ & $\lambda=0.1667$ & $\lambda=0.0952$ \\
\hline NMV-Car & Weibull/Gamma/Weibull & $\begin{array}{l}\alpha=2.7386 \\
\beta=2.2586\end{array}$ & $\begin{array}{l}\alpha=0.8 \\
\beta=2.5\end{array}$ & $\begin{array}{l}\alpha=0.9181 \\
\beta=3.8552\end{array}$ \\
\hline Truck-Car & Gamma & $\begin{array}{l}\alpha=2.8 \\
\beta=7.5\end{array}$ & $\begin{array}{c}\alpha=0.5424 \\
\beta=6.058\end{array}$ & $\begin{array}{c}\alpha=0.5952 \\
\beta=5.6\end{array}$ \\
\hline Car-Truck & Gamma & $\begin{array}{l}\alpha=3.372 \\
\beta=1.6697\end{array}$ & $\begin{array}{l}\alpha=1.2648 \\
\beta=2.4848\end{array}$ & $\begin{array}{l}\alpha=5.9314 \\
\beta=0.3091\end{array}$ \\
\hline \multicolumn{5}{|c|}{ Eastbound traffic } \\
\hline TW-TW & Gamma/Weibull & $\begin{array}{c}\alpha=2.7273 \\
\beta=5.5\end{array}$ & $\begin{array}{l}\alpha=0.9623 \\
\beta=4.6738\end{array}$ & $\begin{array}{l}\alpha=0.7891 \\
\beta=8.6001\end{array}$ \\
\hline Truck-Truck & Weibull/Lognormal & $\begin{array}{l}\alpha=0.8162 \\
\beta=2.3996\end{array}$ & $\begin{array}{l}\alpha=1.1107 \\
\beta=1.0983\end{array}$ & $\begin{array}{l}\sigma=0.5282 \\
\mu=0.9134\end{array}$ \\
\hline Car-Car & Weibull/Exponential/Lognormal & $\begin{array}{l}\alpha=1.4089 \\
\beta=5.7963\end{array}$ & $\lambda=0.1842$ & $\begin{array}{l}\sigma=1.1693 \\
\mu=1.6869\end{array}$ \\
\hline TW-NMV & Exponential/Gamma/Lognormal & $\lambda=0.8$ & $\begin{array}{l}\alpha=2.3364 \\
\beta=1.5987\end{array}$ & $\begin{array}{l}\sigma=1.1629 \\
\mu=1.7253\end{array}$ \\
\hline TW-Truck & Exponential/Gamma & $\lambda=0.2727$ & $\begin{array}{l}\alpha=0.9964 \\
\beta=5.0179\end{array}$ & $\begin{array}{l}\alpha=0.4424 \\
\beta=23.896\end{array}$ \\
\hline TW-Car & Lognormal/Gamma & $\begin{array}{c}\sigma=0.9045 \\
\mu=1.186\end{array}$ & $\begin{array}{l}\alpha=0.5084 \\
\beta=26.798\end{array}$ & $\begin{array}{l}\alpha=0.4424 \\
\beta=23.896\end{array}$ \\
\hline Car-NMV & Weibull/Exponential/Lognormal & $\begin{aligned} \alpha & =1.2046 \\
\beta & =8.3541\end{aligned}$ & $\lambda=0.2$ & $\begin{array}{l}\sigma=1.1816 \\
\mu=1.3591\end{array}$ \\
\hline Car-TW & Weibull/Lognormal & $\begin{array}{l}\alpha=1.0046 \\
\beta=3.1969\end{array}$ & $\begin{array}{l}\sigma=1.2035 \\
\mu=1.5685\end{array}$ & $\begin{array}{l}\sigma=1.1654 \\
\mu=1.5582\end{array}$ \\
\hline Truck-NMV & Gamma & $\begin{array}{l}\alpha=0.3428 \\
\beta=0.8333\end{array}$ & $\begin{aligned} \alpha & =1.1006 \\
\beta & =9.2160\end{aligned}$ & $\begin{array}{l}\alpha=4.6384 \\
\beta=0.3449\end{array}$ \\
\hline Truck-TW & Weibull/Gamma/Exponential & $\begin{array}{l}\alpha=1.4977 \\
\beta=2.8802\end{array}$ & $\begin{array}{l}\alpha=1.1801 \\
\beta=3.7527\end{array}$ & $\lambda=0.3$ \\
\hline NMV-Truck & Gamma/Exponential/Gamma & $\begin{aligned} \alpha & =1.2255 \\
\beta & =0.8333\end{aligned}$ & $\lambda=1.16667$ & $\begin{aligned} \alpha & =2.7162 \\
\beta & =0.8836\end{aligned}$ \\
\hline \begin{tabular}{|l} 
NMV-NMV \\
\end{tabular} & Exponential & $\lambda=2$ & $\lambda=0.4285$ & $\lambda=0.0833$ \\
\hline NMV-TW & Exponential & $\lambda=0.6364$ & $\lambda=0.3044$ & $\lambda=0.0822$ \\
\hline NMV-Car & Exponential/Gamma/Lognormal & $\lambda=0.6666$ & $\begin{aligned} \alpha & =0.9446 \\
\beta & =8.0453\end{aligned}$ & $\begin{array}{l}\sigma=0.8364 \\
\mu=4.9533\end{array}$ \\
\hline Truck-Car & Lognormal/Weibull/Gamma & $\begin{aligned} \sigma & =0.9248 \\
\mu & =1.1662\end{aligned}$ & $\begin{array}{l}\alpha=1.0524 \\
\beta=3.5055\end{array}$ & $\begin{array}{c}\alpha=0.6884 \\
\beta=6.088\end{array}$ \\
\hline Car-Truck & Weibull/Gamma & $\begin{array}{c}\alpha=1.9138 \\
\beta=4.361\end{array}$ & $\begin{array}{l}\alpha=1.2056 \\
\beta=3.1907\end{array}$ & $\begin{array}{l}\alpha=3.7501 \\
\beta=0.7647\end{array}$ \\
\hline
\end{tabular}


a)

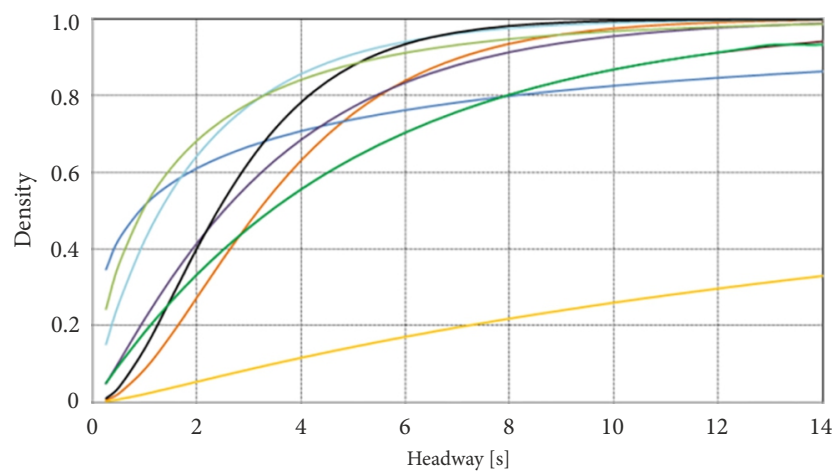

c)

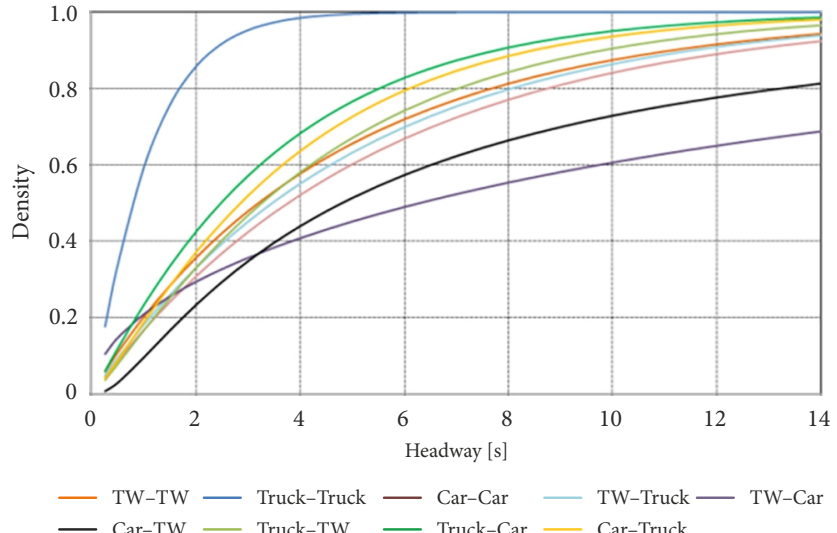

b)

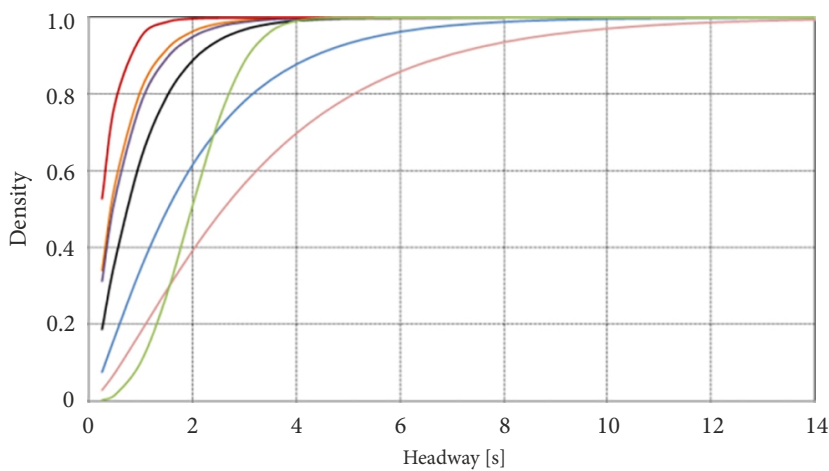

d)

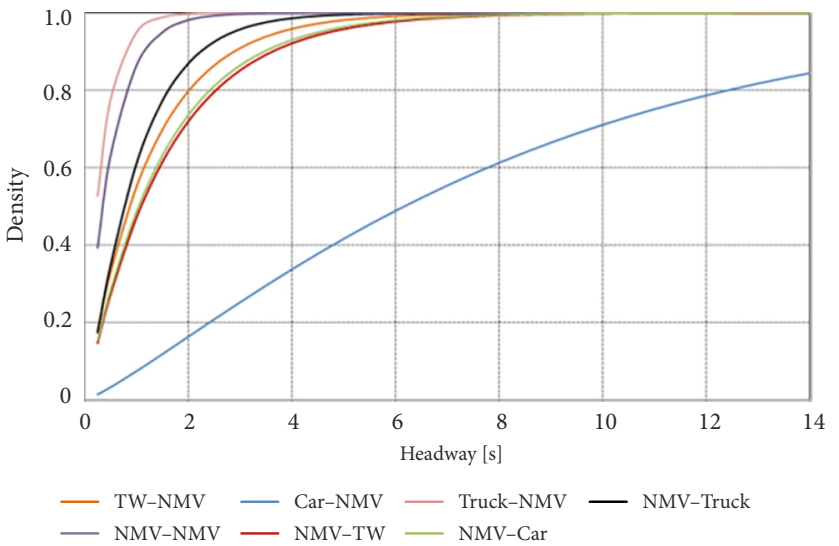

Figure 4. Predicted vehicle-type-specific headway distribution models at low flow: a, b - westbound traffic; c, d - eastbound traffic

a)

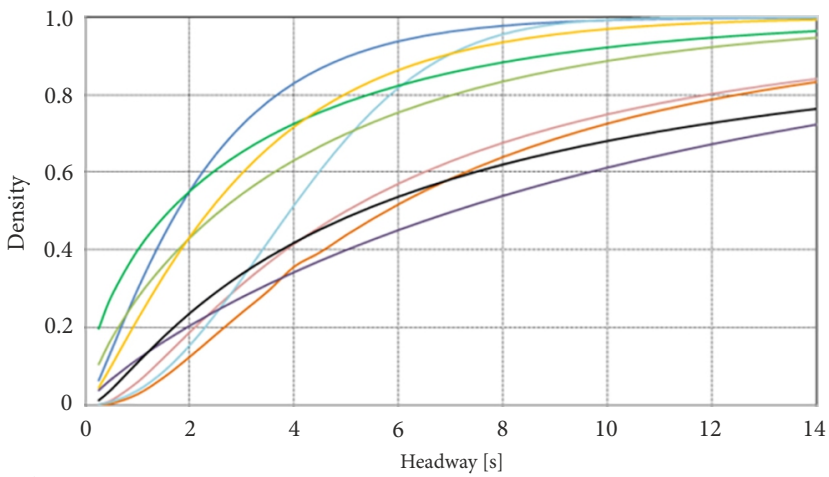

c)

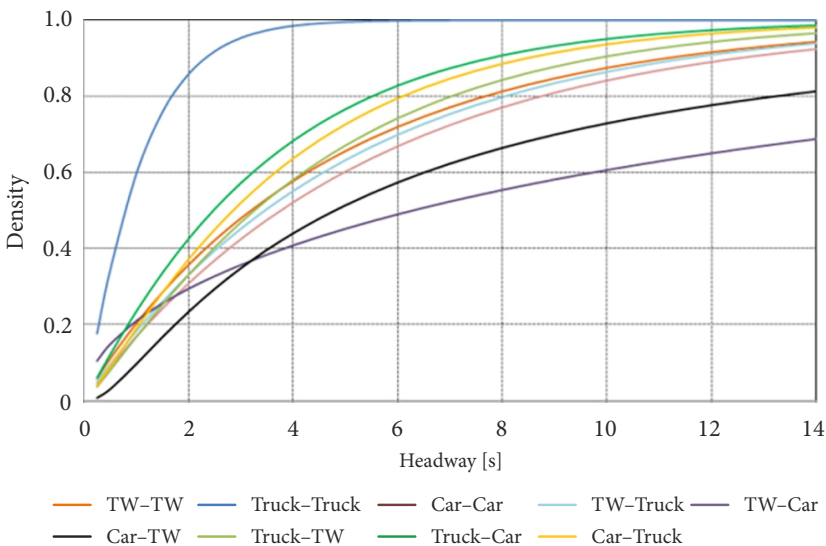

b)

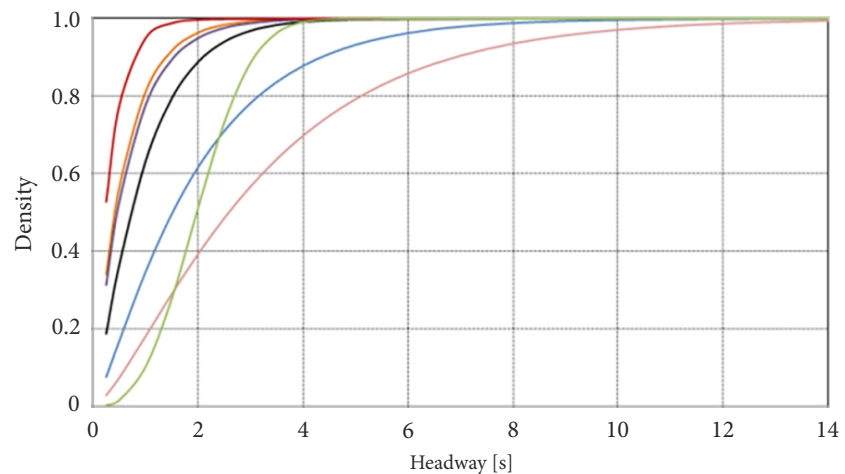

d)

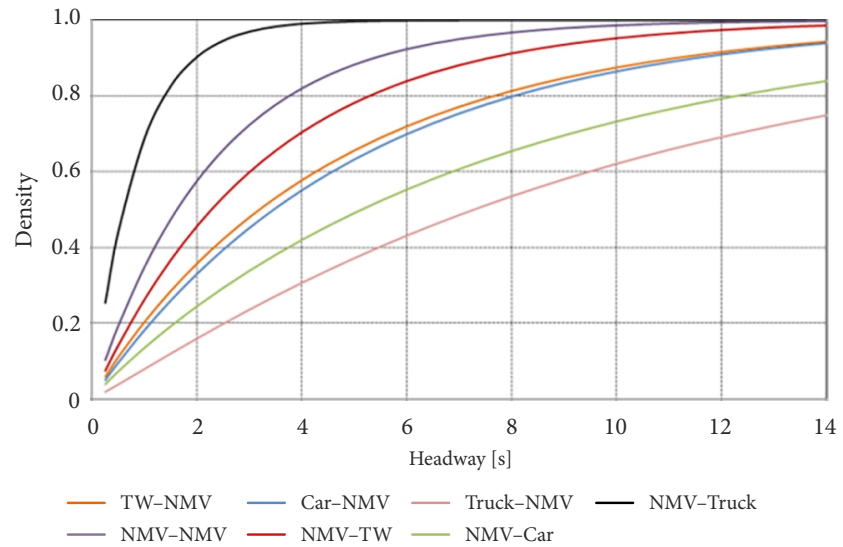

Figure 5. Predicted vehicle-type-specific headway distribution models at moderate flow: $a, b$ - westbound traffic; $c, d$ - eastbound traffic 
a)

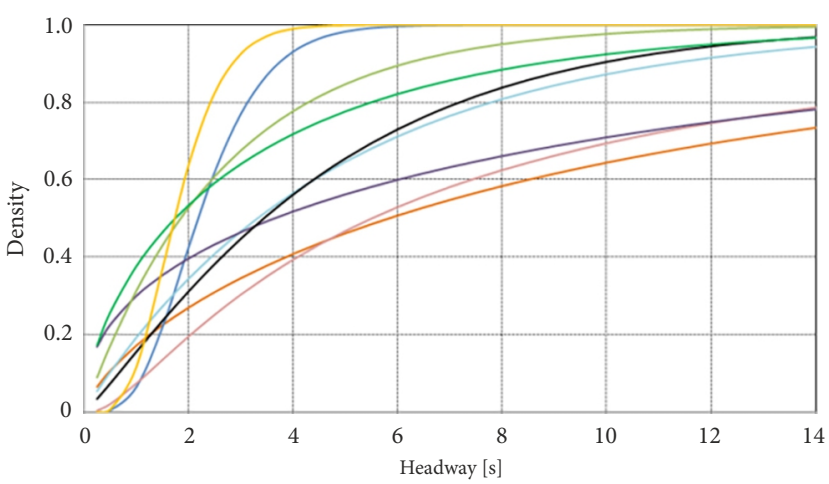

c)

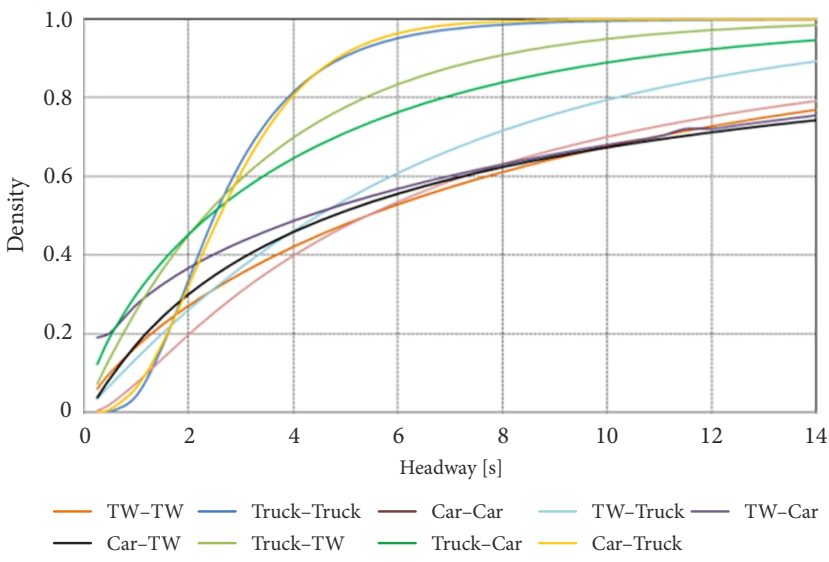

b)

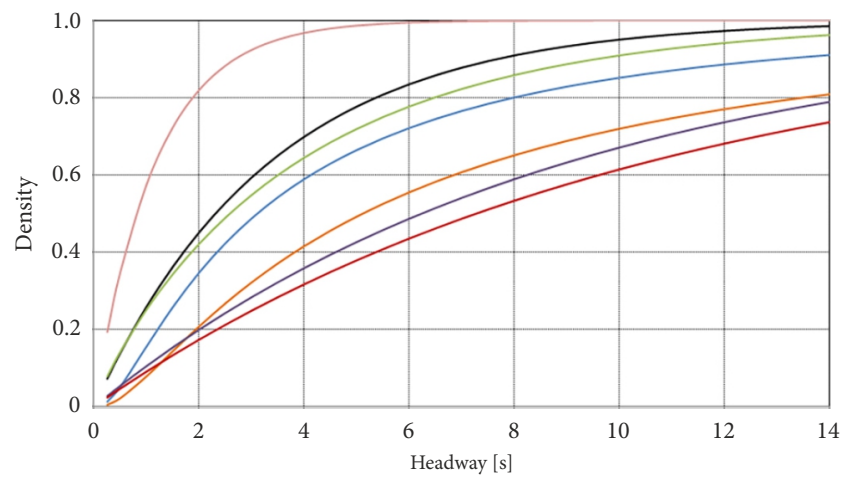

d)

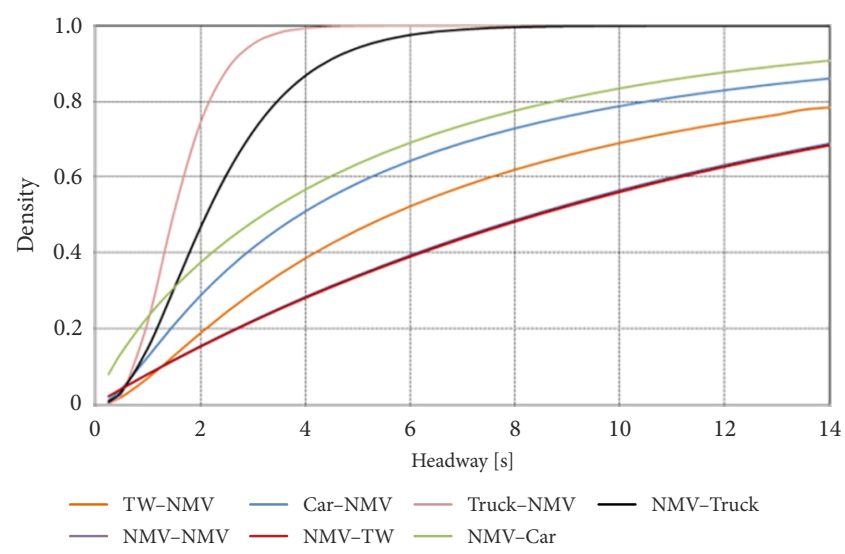

Figure 6. Predicted vehicle-type-specific headway distribution models at heavy flow: a, b - westbound traffic; c, $d$ - eastbound traffic

Empirical observations, thus, make it clear that drivers adjust their headways on the basis of types of vehicles they are following and it significantly varies across vehicle types. Thus, distributions of vehicle-type-specific headways are fairly different for different vehicle groups and it is particularly true for mixed traffic composed of a wide range of vehicle types. Accordingly, it results error in estimating Percent Time Spent Following (PTSF), a major performance measure for the assessment of levelof-service, and, thereby, inaccurate assessment of traffic performance as a consequence.

Further, pilot studies were conducted on different highway sections, which exhibit similar traffic characteristics to observe the amount of accuracy of the model outcomes with the field data. The accuracy level was calculated using Standard Error of Estimate (SEE). It was observed that the data points generated based on field observations and model estimations are very close to the anticipated line of agreement (Figure 7), thereby, indicating satisfactory agreement between the field probabilities and model outcomes.

\section{Discussions}

Most of the vehicle-type-specific headway studies conducted so far are based on homogeneous traffic, which is distinctly different than the mixed traffic considered in the paper. As a matter of fact, those studies considered only the effect of car and truck in the analysis and reported that traffic flow rate, percentage of trucks, lane positions have impact on headway distribution. Since mixed traffic is composed of a wide range of vehicle types, distribution of headways are affected by multiple variables attributable to the changing headway characteristics of different vehicle pairs. Further, even a same vehicle category, for instance, a car, was observed to have large variations in vehicle dynamics. Collectively, they have significant impact on headway distribution under such traffic.

An attempt was, therefore, made in the paper to compare the calculated headway probabilities with those obtained from more or less homogeneous traffic (Table 6). It was observed that in urban scenario probability of car-car headway is high because of the regimented flow of traffic. However, on freeways or highways usually car drivers move with widely spaced headways. Table 6 indicates that probability of shorter headways is in the range of $0.11 \ldots 0.22$ if the traffic is homogeneous in character. Such probabilities, however, turn out to be almost double under mixed traffic. In case of Car-Truck headways, the values in general increase further indicating risk-taking behaviour of driver population. Interestingly, no significant difference in driver's behaviour was observed in case of truck-followed headways. 
Table 5. Probabilities of vehicle-type-specific headways computed based on predictive models

\begin{tabular}{|c|c|c|c|c|c|c|c|}
\hline Headway $[\mathrm{s}] \rightarrow$ & 1 & 3 & 5 & 7 & 9 & 11 & 13 \\
\hline Headway type $\downarrow$ & \multicolumn{7}{|c|}{ Probability of headway less than $t[\mathrm{~s}]$} \\
\hline \multicolumn{8}{|c|}{ Westbound traffic } \\
\hline \multicolumn{8}{|c|}{ Low traffic flow level (<400 veh/h) } \\
\hline TW-W & 0.0863 & 0.468 & 0.7535 & 0.8975 & 0.9601 & 0.9851 & 0.9946 \\
\hline Truck-Truck & 0.5147 & 0.6677 & 0.7382 & 0.7823 & 0.8134 & 0.8368 & 0.8553 \\
\hline Car-Car & 0.1836 & 0.4559 & 0.6374 & 0.7584 & 0.8389 & 0.8926 & 0.9285 \\
\hline TW-NMV & 0.8111 & 0.9933 & 0.9997 & 0.9999 & 0.9999 & 0.9999 & 0.9999 \\
\hline TW-Truck & 0.4244 & 0.7751 & 0.9086 & 0.9623 & 0.9898 & 0.9934 & 0.9972 \\
\hline TW-Car & 0.2182 & 0.5695 & 0.7712 & 0.8801 & 0.9377 & 0.9678 & 0.9835 \\
\hline Car-NMV & 0.3465 & 0.7825 & 0.9330 & 0.9800 & 0.9941 & 0.9983 & 0.9995 \\
\hline Car-TW & 0.1408 & 0.6280 & 0.8792 & 0.9656 & 0.9909 & 0.9977 & 0.9994 \\
\hline Truck-NMV & 0.1805 & 0.5675 & 0.7929 & 0.9050 & 0.9575 & 0.9813 & 0.9919 \\
\hline Truck-TW & 0.5112 & 0.7801 & 0.8830 & 0.9327 & 0.9594 & 0.9746 & 0.9837 \\
\hline NMV-Truck & 0.6321 & 0.9693 & 0.9980 & 0.9999 & 1.0000 & 1.0000 & 1.0000 \\
\hline NMV-NMV & 0.7769 & 0.9889 & 0.9994 & 1.0000 & 1.0000 & 1.0000 & 1.0000 \\
\hline NMV-TW & 0.9502 & 0.9999 & 1.0000 & 1.0000 & 1.0000 & 1.0000 & 1.0000 \\
\hline NMV-Car & 0.1018 & 0.8865 & 0.9999 & 1.0000 & 1.0000 & 1.0000 & 1.0000 \\
\hline Truck-Car & 0.1836 & 0.4559 & 0.6374 & 0.7584 & 0.8390 & 0.8927 & 0.9330 \\
\hline Car-Truck & 0.0211 & 0.0854 & 0.1441 & 0.1950 & 0.2394 & 0.2785 & 0.3132 \\
\hline \multicolumn{8}{|c|}{ Moderate traffic flow level $(500 \ldots 700 \mathrm{veh} / \mathrm{h})$} \\
\hline TW-W & 0.0286 & 0.2394 & 0.4392 & 0.5843 & 0.6865 & 0.7593 & 0.8121 \\
\hline Truck-Truck & 0.3000 & 0.7226 & 0.8974 & 0.9631 & 0.9869 & 0.9954 & 0.9984 \\
\hline Car-Car & 0.0602 & 0.3118 & 0.5013 & 0.6288 & 0.7163 & 0.7781 & 0.8231 \\
\hline TW-NMV & 0.1701 & 0.3879 & 0.5397 & 0.6510 & 0.7340 & 0.7966 & 0.8440 \\
\hline TW-Truck & 0.0383 & 0.3269 & 0.6872 & 0.9058 & 0.9819 & 0.9978 & 0.9998 \\
\hline TW-Car & 0.1189 & 0.2787 & 0.4003 & 0.4979 & 0.5778 & 0.6439 & 0.6991 \\
\hline Car-NMV & 0.1911 & 0.4708 & 0.6538 & 0.7735 & 0.8518 & 0.9030 & 0.9366 \\
\hline Car-TW & 0.1104 & 0.3388 & 0.4842 & 0.5825 & 0.6529 & 0.7058 & 0.7467 \\
\hline Truck-NMV & 0.5276 & 0.8946 & 0.9765 & 0.9948 & 0.9988 & 0.9997 & 0.9999 \\
\hline Truck-TW & 0.2774 & 0.5447 & 0.7001 & 0.7988 & 0.8636 & 0.9068 & 0.9361 \\
\hline NMV-Truck & 0.7769 & 0.9889 & 0.9994 & 1.0000 & 1.0000 & 1.0000 & 1.0000 \\
\hline NMV-NMV & 0.1198 & 0.3182 & 0.4718 & 0.5908 & 0.6830 & 0.7545 & 0.8098 \\
\hline NMV-TW & 0.3486 & 0.7235 & 0.8827 & 0.9502 & 0.9789 & 0.9910 & 0.9962 \\
\hline NMV-Car & 0.4349 & 0.7748 & 0.9057 & 0.9597 & 0.9826 & 0.9924 & 0.9967 \\
\hline Truck-Car & 0.4003 & 0.6530 & 0.7812 & 0.8573 & 0.9051 & 0.9361 & 0.9566 \\
\hline Car-Truck & 0.2224 & 0.5983 & 0.8036 & 0.9062 & 0.9558 & 0.9794 & 0.9904 \\
\hline \multicolumn{8}{|c|}{ Heavy traffic flow level $(800 \ldots 1000 \mathrm{veh} / \mathrm{h})$} \\
\hline TW-W & 0.1717 & 0.3458 & 0.4615 & 0.5479 & 0.6155 & 0.6700 & 0.7148 \\
\hline Truck-Truck & 0.0641 & 0.7696 & 0.9825 & 0.9992 & 1.0000 & 1.0000 & 1.0000 \\
\hline Car-Car & 0.0739 & 0.3034 & 0.4677 & 0.5811 & 0.6621 & 0.7219 & 0.7674 \\
\hline TW-NMV & 0.0785 & 0.3218 & 0.4921 & 0.6072 & 0.6879 & 0.7466 & 0.7906 \\
\hline TW-Truck & 0.1926 & 0.4666 & 0.6461 & 0.7648 & 0.8435 & 0.8958 & 0.9306 \\
\hline TW-Car & 0.2997 & 0.4646 & 0.5622 & 0.6324 & 0.6866 & 0.7301 & 0.7659 \\
\hline Car-NMV & 0.1560 & 0.4875 & 0.6643 & 0.7655 & 0.8285 & 0.8702 & 0.8991 \\
\hline Car-TW & 0.1555 & 0.4474 & 0.6547 & 0.7902 & 0.8752 & 0.9270 & 0.9579 \\
\hline Truck-NMV & 0.5756 & 0.9236 & 0.9862 & 0.9975 & 0.9996 & 0.9999 & 1.0000 \\
\hline Truck-TW & 0.3127 & 0.6753 & 0.8466 & 0.9276 & 0.9658 & 0.9838 & 0.9924 \\
\hline NMV-Truck & 0.2592 & 0.5934 & 0.7769 & 0.8775 & 0.9328 & 0.9631 & 0.9798 \\
\hline NMV-NMV & 0.1052 & 0.2835 & 0.4262 & 0.5406 & 0.6321 & 0.7054 & 0.7641 \\
\hline NMV-TW & 0.0908 & 0.2485 & 0.3789 & 0.4866 & 0.5756 & 0.6492 & 0.7101 \\
\hline NMV-Car & 0.2515 & 0.5481 & 0.7191 & 0.8226 & 0.8867 & 0.9271 & 0.9528 \\
\hline Truck-Car & 0.3763 & 0.6404 & 0.7763 & 0.8566 & 0.9064 & 0.9383 & 0.9589 \\
\hline Car-Truck & 0.1155 & 0.9248 & 0.9989 & 1.0000 & 1.0000 & 1.0000 & 1.0000 \\
\hline
\end{tabular}


End of Table 5

\begin{tabular}{|c|c|c|c|c|c|c|c|}
\hline Headway $[s] \rightarrow$ & 1 & 3 & 5 & 7 & 9 & 11 & 13 \\
\hline Headway type $\downarrow$ & \multicolumn{7}{|c|}{ Probability of headway less than $t[\mathrm{~s}]$} \\
\hline \multicolumn{8}{|c|}{ Eastbound traffic } \\
\hline \multicolumn{8}{|c|}{ Low traffic flow level $(<400 \mathrm{veh} / \mathrm{h})$} \\
\hline TW-TW & 0.0019 & 0.0300 & 0.0937 & 0.1831 & 0.2854 & 0.3901 & 0.4899 \\
\hline Truck-Truck & 0.3871 & 0.6988 & 0.8381 & 0.9089 & 0.9472 & 0.9687 & 0.9811 \\
\hline Car-Car & 0.0807 & 0.3267 & 0.5563 & 0.7289 & 0.8443 & 0.9152 & 0.9560 \\
\hline TW-NMV & 0.5507 & 0.9093 & 0.9817 & 0.9963 & 0.9993 & 0.9998 & 1.0000 \\
\hline TW-Truck & 0.2387 & 0.5588 & 0.7443 & 0.8518 & 0.9141 & 0.9502 & 0.9711 \\
\hline TW-Car & 0.0949 & 0.4615 & 0.6801 & 0.7996 & 0.8682 & 0.9098 & 0.9363 \\
\hline Car-NMV & 0.0746 & 0.2526 & 0.4166 & 0.5543 & 0.6651 & 0.7517 & 0.8180 \\
\hline Car-TW & 0.2674 & 0.6086 & 0.7914 & 0.8889 & 0.9409 & 0.9686 & 0.9833 \\
\hline Truck-NMV & 0.9502 & 0.9999 & 1.0000 & 1.0000 & 1.0000 & 1.0000 & 1.0000 \\
\hline Truck-TW & 0.1854 & 0.6546 & 0.8982 & 0.9772 & 0.9960 & 0.9994 & 0.9999 \\
\hline NMV-Truck & 0.6110 & 0.9579 & 0.9958 & 0.9996 & 1.0000 & 1.0000 & 1.0000 \\
\hline NMV-NMV & 0.8647 & 0.9975 & 1.0000 & 1.0000 & 1.0000 & 1.0000 & 1.0000 \\
\hline NMV-TW & 0.4708 & 0.8518 & 0.9585 & 0.9884 & 0.9967 & 0.9991 & 0.9997 \\
\hline NMV-Car & 0.4866 & 0.8647 & 0.9643 & 0.9906 & 0.9975 & 0.9993 & 0.9998 \\
\hline Truck-Car & 0.1037 & 0.4709 & 0.6841 & 0.8004 & 0.8675 & 0.9085 & 0.9348 \\
\hline Car-Truck & 0.0580 & 0.3866 & 0.7272 & 0.9157 & 0.9817 & 0.9972 & 0.9997 \\
\hline \multicolumn{8}{|c|}{ Moderate traffic flow level $(500 \ldots 700 \mathrm{veh} / \mathrm{h})$} \\
\hline TW-TW & 0.2029 & 0.4794 & 0.6560 & 0.7712 & 0.8472 & 0.8976 & 0.9312 \\
\hline Truck-Truck & 0.5955 & 0.9534 & 0.9955 & 0.9996 & 1.0000 & 1.0000 & 1.0000 \\
\hline Car-Car & 0.1682 & 0.4246 & 0.6019 & 0.7246 & 0.8095 & 0.8682 & 0.9088 \\
\hline TW-NMV & 0.0790 & 0.4634 & 0.7557 & 0.9015 & 0.9631 & 0.9868 & 0.9954 \\
\hline TW-Truck & 0.1820 & 0.4518 & 0.6324 & 0.7534 & 0.8346 & 0.8890 & 0.9255 \\
\hline TW-Car & 0.2093 & 0.3570 & 0.4518 & 0.5235 & 0.5812 & 0.6292 & 0.6698 \\
\hline Car-NMV & 0.1813 & 0.4512 & 0.6321 & 0.7534 & 0.8347 & 0.8892 & 0.9257 \\
\hline Car-TW & 0.0962 & 0.3481 & 0.5136 & 0.6231 & 0.6993 & 0.7546 & 0.7962 \\
\hline Truck-NMV & 0.0784 & 0.2352 & 0.3712 & 0.4852 & 0.5798 & 0.6576 & 0.7214 \\
\hline Truck-TW & 0.1672 & 0.4686 & 0.6708 & 0.7988 & 0.8780 & 0.9264 & 0.9558 \\
\hline NMV-Truck & 0.6886 & 0.9698 & 0.9971 & 0.9997 & 1.0000 & 1.0000 & 1.0000 \\
\hline NMV-NMV & 0.3486 & 0.7235 & 0.8827 & 0.9502 & 0.9789 & 0.9910 & 0.9962 \\
\hline NMV-TW & 0.2624 & 0.5987 & 0.7817 & 0.8812 & 0.9354 & 0.9648 & 0.9809 \\
\hline NMV-Car & 0.1345 & 0.3381 & 0.4905 & 0.6066 & 0.6958 & 0.7644 & 0.8174 \\
\hline Truck-Car & 0.2344 & 0.5721 & 0.7662 & 0.8739 & 0.9326 & 0.9643 & 0.9812 \\
\hline Car-Truck & 0.1889 & 0.5201 & 0.7264 & 0.8466 & 0.9148 & 0.9530 & 0.9742 \\
\hline \multicolumn{8}{|c|}{ Heavy traffic flow level $(800 \ldots 1000 \mathrm{veh} / \mathrm{h})$} \\
\hline TW-TW & 0.1673 & 0.3531 & 0.4789 & 0.5726 & 0.6453 & 0.7031 & 0.7498 \\
\hline Truck-Truck & 0.0419 & 0.6371 & 0.9062 & 0.9747 & 0.9925 & 0.9975 & 0.9991 \\
\hline Car-Car & 0.0746 & 0.3074 & 0.4736 & 0.5877 & 0.6687 & 0.7284 & 0.7736 \\
\hline TW-NMV & 0.0690 & 0.2950 & 0.4603 & 0.5752 & 0.6576 & 0.7185 & 0.7649 \\
\hline TW-Truck & 0.1370 & 0.3685 & 0.5408 & 0.6670 & 0.7589 & 0.8256 & 0.8740 \\
\hline TW-Car & 0.2738 & 0.4341 & 0.5310 & 0.6017 & 0.6569 & 0.7017 & 0.7390 \\
\hline Car-NMV & 0.1250 & 0.4128 & 0.5839 & 0.6903 & 0.7609 & 0.8103 & 0.8463 \\
\hline Car-TW & 0.1731 & 0.3906 & 0.5124 & 0.5927 & 0.6504 & 0.6942 & 0.7286 \\
\hline Truck-NMV & 0.2183 & 0.9514 & 0.9992 & 1.0000 & 1.0000 & 1.0000 & 1.0000 \\
\hline Truck-TW & 0.2592 & 0.5934 & 0.7769 & 0.8775 & 0.9328 & 0.9631 & 0.9798 \\
\hline NMV-Truck & 0.1481 & 0.7197 & 0.9415 & 0.9900 & 0.9985 & 0.9998 & 1.0000 \\
\hline NMV-NMV & 0.0800 & 0.2212 & 0.3407 & 0.4420 & 0.5276 & 0.6001 & 0.6615 \\
\hline NMV-TW & 0.0789 & 0.2185 & 0.3370 & 0.4375 & 0.5227 & 0.5951 & 0.6565 \\
\hline NMV-Car & 0.2307 & 0.4818 & 0.6350 & 0.7370 & 0.8075 & 0.8576 & 0.8937 \\
\hline Truck-Car & 0.3003 & 0.5628 & 0.7116 & 0.8056 & 0.8673 & 0.9086 & 0.9367 \\
\hline Car-Truck & 0.0632 & 0.6093 & 0.9138 & 0.9860 & 0.9981 & 0.9998 & 1.0000 \\
\hline
\end{tabular}


a)

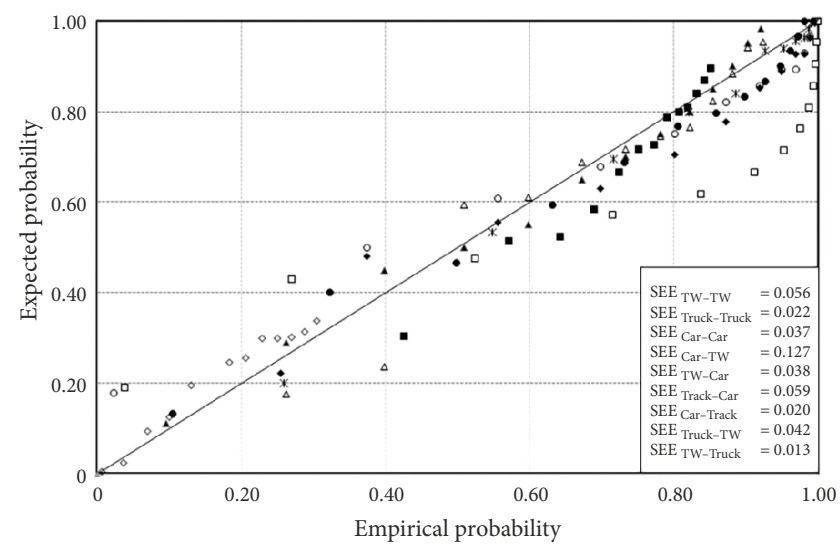

c)

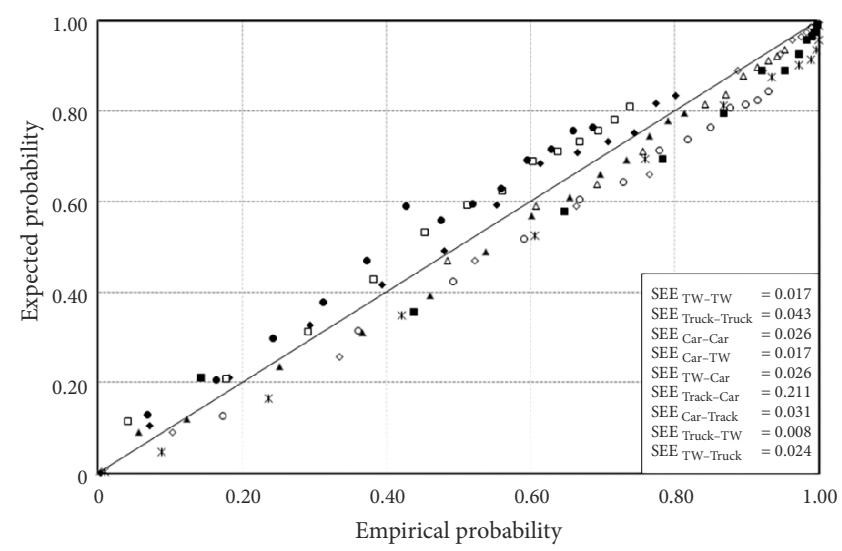

b)

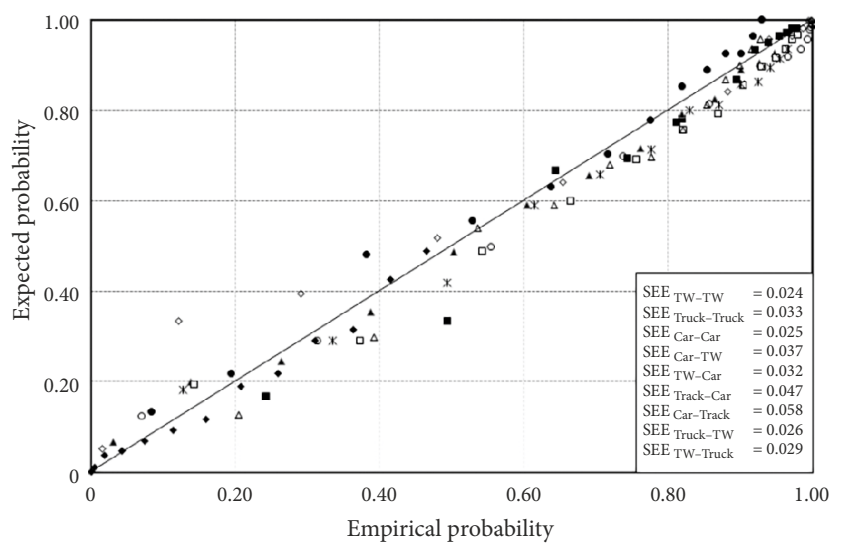

d)

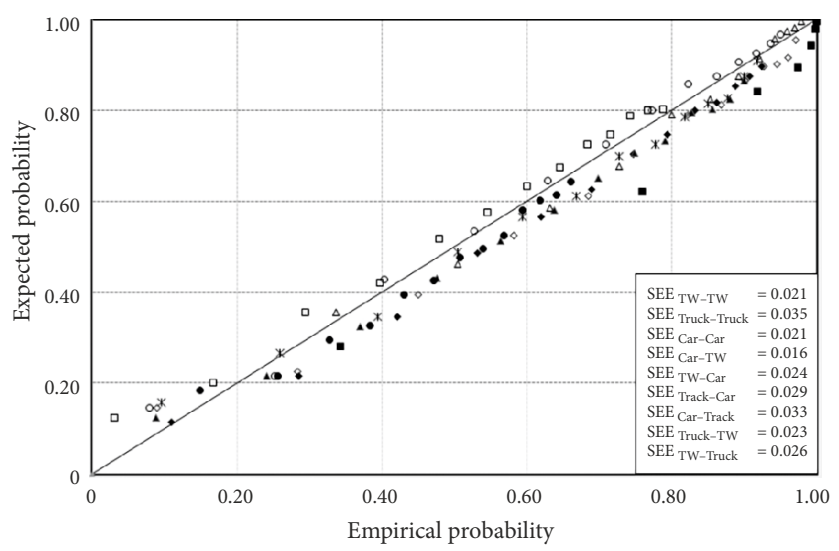

- TW-TW - Truck-Truck $\Delta$ Car-Car $\quad$ C Car-TW •TW-Car $\Delta$ Truck-Car $\diamond$ Car-Truck $\circ$ Truck-TW * TW-Truck

Figure 7. Agreement between the probabilities of headways obtained from the models and pilot studies (both direction traffic): a, b - model output versus pilot study in westbound; $c, d$ - model output versus pilot study in eastbound

Table 6. Comparison of headway probabilities: current study and case studies with homogeneous traffic

\begin{tabular}{|c|c|c|c|c|c|}
\hline Probability of headway less than $t[\mathrm{~s}] \rightarrow$ & 2 & 4 & 6 & 8 & 10 \\
\hline \multicolumn{6}{|c|}{ Car-Car headway type } \\
\hline Study in Singapore (Weng et al. 2014) & 0.58 & 0.90 & 0.97 & 0.99 & 0.99 \\
\hline Study in Greenfield, Massachusetts, US (Dong et al. 2015) & 0.11 & 0.22 & 0.58 & 0.68 & 0.86 \\
\hline Current study & 0.19 & 0.40 & 0.45 & 0.62 & 0.70 \\
\hline \multicolumn{6}{|c|}{ Car-Truck headway type } \\
\hline Study in Singapore (Weng et al. 2014) & 0.42 & 0.85 & 0.95 & 0.98 & 0.99 \\
\hline Study in Greenfield, Massachusetts, US (Dong et al. 2015) & 0.10 & 0.21 & 0.42 & 0.58 & 0.78 \\
\hline Current study & 0.62 & 0.98 & 0.99 & 0.99 & 0.99 \\
\hline \multicolumn{6}{|c|}{ Truck-Car headway type } \\
\hline Study in Singapore (Weng et al. 2014) & 0.44 & 0.78 & 0.82 & 0.92 & 0.94 \\
\hline Current study & 0.58 & 0.70 & 0.82 & 0.90 & 0.92 \\
\hline \multicolumn{6}{|c|}{ Truck-Truck headway type } \\
\hline Study in Singapore (Weng et al. 2014) & 0.38 & 0.68 & 0.82 & 0.90 & 0.96 \\
\hline Current study & 0.38 & 0.82 & 0.96 & 0.98 & 0.99 \\
\hline
\end{tabular}

\section{Conclusions}

At car-following state under mixed traffic, headway between two vehicles depends on the type of lead vehicle and largely influenced by its size and dynamics. Since, time headway of vehicles is an important traffic flow characteris- tics, which affect capacity, level-of-service and safety analysis, it is important to know the specific distribution for a particular roadway and traffic condition. In this paper, an attempt was, thus, made to analyse vehicle-type-specific 
headways on the basis of field data collected on two-lane rural roads in India. The observed vehicles were classified into six types: car, TW, bus, truck, three-wheeler and NMV. However, presence of bus and three-wheelers in the traffic flow was significantly low compared to the rest. Thus, four vehicle types and their sixteen combinations (leader-follower) were considered for analysis.

It was observed that under mixed traffic, TW-TW combination has smallest headway in most of the instances whereas it was fairly large in case of Truck-Truck combination. Observations indicate that mostly bike riders are reluctant to obey lane discipline under such traffic and they move with very short headways to perform overtaking. Further, truck-followed mean headways were observed to be larger than the car-followed mean headway, making it evident that while following a truck drivers take more conservative attitude than that of a car because of the larger size of truck and lower braking capability. While following NMV, drivers were observed keep reasonably safe distances. This was, however, quite the opposite in the event of a motorised vehicle followed by a NMV one; this could be due to low speed potential of NMV.

A comparison of headway probabilities obtained based on current investigation with those observed on roads displaying homogeneous traffic was also made to understand the impact of mixed traffic on vehicle headways. It was found that under mixed traffic probability of shorter headways is high for car-car combination, which however further increases for car-truck combination. This is attributable to high risk-taking behaviour of driver population. Interestingly, no significant change was noticed in truck driver's behaviour.

This paper thus demonstrates the necessity of investigating vehicle-type-specific headways under mixed traffic. The study is based on data collected from three road sections and, thus, calls for further initiatives in conducting such investigation based on comprehensive field data. Further, few more distributions may be fitted to the data in order to improve the predictive performance of the models.

\section{Acknowledgements}

The part of the analysis presented in the paper has used the data collected in the CSIR-CRRI, New Delhi sponsored project "Development of Indian Highway Capacity Manual (INDO-HCM)".

The authors sincerely acknowledge CSIR-CRRI.

\section{References}

Abtahi, S. M.; Tamannaei, M.; Haghshenash, H. 2011. Analysis and modeling time headway distributions under heavy traffic flow conditions in the urban highways: case of Isfahan, Transport 26(4): 375-382.

https://doi.org/10.3846/16484142.2011.635694

Al-Ghamdi, A. S 2001. Analysis of time headways on urban roads: case study from Riyadh, Journal of Transportation Engineering 127(4): 289-294.

https://doi.org/10.1061/(ASCE)0733-947X(2001)127:4(289)
Arasan, V. T.; Koshy, R. Z. 2003. Headway distribution of heterogeneous traffic on urban arterials, Journal of the Institution of Engineers (India): Civil Engineering Division 84: 210-215.

Branston, D. 1976. Models of single lane time headway distributions, Transportation Science 10(2): 125-148.

https://doi.org/10.1287/trsc.10.2.125

Chandra, S.; Kumar, R. 2001. Headway modelling under mixed traffic on urban roads, Road and Transport Research 10(1): 61-71.

Cowan, R. J. 1975. Useful headway models, Transportation Research 9(6): 371-375.

https://doi.org/10.1016/0041-1647(75)90008-8

Dey, P. P; Chandra, S. 2009. Desired time gap and time headway in steady-state car-following on two-lane roads, Journal of Transportation Engineering 135(10): 687-693. https://doi.org/10.1061/(ASCE)0733-947X(2009)135:10(687)

Dong, S.; Wang, H.; Hurwitz, D.; Zhang, G.; Shi, J. 2015. Nonparametric modeling of vehicle-type-specific headway distribution in freeway work zones, Journal of Transportation Engineering 141(11): 05015004.

https://doi.org/10.1061/(ASCE)TE.1943-5436.0000788

Greenberg, I. 1966. The log-normal distribution of headways, Australian Road Research 2(7): 14-18.

Jang, J.; Park, C.; Kim, B.; Choi, N. 2011. Modeling of time headway distribution on suburban arterial: case study from South Korea, Procedia - Social and Behavioral Sciences 16: 240-247. https://doi.org/10.1016/j.sbspro.2011.04.446

Khasnabis, S.; Heimbach, C. L. 1980. Headway-distribution models for two-lane rural highways, Transportation Research Record: Journal of the Transportation Research Board 772: 44-51.

Kominek, Z. 2002. Minimum chi-squared estimation of stable distributions parameters: an application to the Warsaw stock exchange, Journal of Applied Statistics 29(5): 729-744. https://doi.org/10.1080/02664760120098793

Kumar, V. M.; Rao, S. K. 1998. Headway and speed studies on two-lane highways, Indian Highways 26(5): 23-36.

Luttinen, R. T. 1999. Properties of Cowan's M3 headway distribution, Transportation Research Record: Journal of the Transportation Research Board 1678: 189-196.

https://doi.org/10.3141/1678-23

Luttinen, R. T. 1996. Statistical Analysis of Vehicle Time Headways. Dissertation for the Degree of Doctor of Technology. Helsinki University of Technology, Finland. 193 p. Available from Internet:

http://lib.tkk.fi/Diss/199X/isbn951228474X/isbn951228474X. pdf

May, A. D. 1990. Traffic Flow Fundamentals. Prentice Hall. 464 p.

Mei, M.; Bullen, A. G. R. 1993. Lognormal distribution for high traffic flows, Transportation Research Record: Journal of the Transportation Research Board 1398: 125-128.

Myung, J. I. 2003. Tutorial on maximum likelihood estimation, Journal of Mathematical Psychology 47(1): 90-100. https://doi.org/10.1016/S0022-2496(02)00028-7

Panichpapiboon, S. 2015. Time-headway distributions on an expressway: case of Bangkok, Journal of Transportation Engineering 141(1): 05014007.

https://doi.org/10.1061/(ASCE)TE.1943-5436.0000731

Penmetsa, P.; Ghosh, I.; Chandra, S. 2015. Evaluation of performance measures for two-lane intercity highways under mixed traffic conditions, Journal of Transportation Engineering 141(10): 04015021.

https://doi.org/10.1061/(ASCE)TE.1943-5436.0000787 
Peeta, S.; Zhang, P.; Zhou, W. 2005. Behavior-based analysis of freeway car-truck interactions and related mitigation strategies, Transportation Research Part B: Methodological 39(5): 417-451. https://doi.org/10.1016/j.trb.2004.06.002

Riccardo, R.; Massimiliano, G. 2012. An empirical analysis of vehicle time headways on rural two-lane two-way roads, Procedia - Social and Behavioral Sciences 54: 865-874.

https://doi.org/10.1016/j.sbspro.2012.09.802

Saha, P.; Roy, R.; Sarkar, A. K.; Pal, M. 2019. Preferred time headway of drivers on two-lane highways with heterogeneous traffic, Transportation Letters: the International Journal of Transportation Research 11(4): 200-2007. https://doi.org/10.1080/19427867.2017.1312859

Saha, P.; Roy, N.; Sarkar, A. K.; Pal, M. 2017a. Speed distribution on two-lane rural highways with mixed traffic: a case study in North East India, Journal of The Institution of Engineers (India): Series A 98(1-2): 107-113.

https://doi.org/10.1007/s40030-017-0208-0

Saha, P.; Sarkar, A. K.; Pal, M. 2017b. Evaluation of speed-flow characteristics on two-lane highways with mixed traffic, Transport 32(4): 331-339. https://doi.org/10.3846/16484142.2015.1004369

Tanyel, S.; Yayla, N. 2003. A discussion on the parameters of Cowan M3 distribution for Turkey, Transportation Research Part A: Policy and Practice 37(2): 129-143. https://doi.org/10.1016/S0965-8564(02)00009-5

Vasconcelos, L.; Bastos Silva, A.; Seco, Á.; Silva, J. 2012. Estimating the parameters of Cowan's M3 headway distribution for roundabout capacity analyses, The Baltic Journal of Road and Bridge Engineering 7(4): 261-268.

https://doi.org/10.3846/bjrbe.2012.35

Wang, X.; Peng, Z. 2014. Method of moments for estimating uncertainty distributions, Journal of Uncertainty Analysis and Applications 2: 5. https://doi.org/10.1186/2195-5468-2-5

Weng, J.; Meng, Q.; Fwa, T. F. 2014. Vehicle headway distribution in work zones, Transportmetrica A: Transport Science 10(4): 285-303. https://doi.org/10.1080/23249935.2012.762564

Ye, F.; Zhang, Y. 2009. Vehicle type-specific headway analysis using freeway traffic data, Transportation Research Record: Journal of the Transportation Research Board 2124: 222-230. https://doi.org/10.3141/2124-22

Yin, S.; Li, Z.; Zhang, Y.; Yao, D.; Su, Y.; Li, L. 2009. Headway distribution modeling with regard to traffic status, in 2009 IEEE Intelligent Vehicles Symposium, 3-5 June 2009, Xi'an, China, 1057-1062. https://doi.org/10.1109/IVS.2009.5164427

Zhang, G.; Wang, Y. 2014. A Gaussian kernel-based approach for modeling vehicle headway distributions, Transportation Science 48(2): 206-216. https://doi.org/10.1287/trsc.1120.0451

Zhang, G.; Wang, Y.; Wei, H.; Chen, Y. 2007. Examining headway distribution models with urban freeway loop event data, Transportation Research Record: Journal of the Transportation Research Board 1999: 141-149. https://doi.org/10.3141/1999-15 